\title{
Isolation and Identification of
} Isocoumarin Derivatives With Specific Inhibitory Activity Against Wnt Pathway and Metabolome Characterization of Lasiodiplodia venezuelensis

\section{OPEN ACCESS}

Edited by:

Alfonso Carotenuto,

University of Naples Federico II, Italy

Reviewed by:

Mario Juan Simirgiotis, Austral University of Chile, Chile

Nutan Kaushik,

Amity University, India

*Correspondence:

Léonie Pellissier

leonie.pellissier@unige.ch

Jean-Luc Wolfender

Jean-Luc.Wolfender@unige.ch

Specialty section: This article was submitted to Medicinal and Pharmaceutical Chemistry,

a section of the journal Frontiers in Chemistry

Received: 20 April 2021

Accepted: 12 July 2021

Published: 12 August 2021

Citation:

Pellissier L, Koval A, Marcourt L, Ferreira Queiroz E, Lecoultre N, Leoni S, Quiros-Guerrero L-M, Barthélémy $M$, Duivelshof $B L$, Guillarme D, Tardy S, Eparvier V, Perron K, Chave Jô, Stien D, Gindro K, Katanaev $V$ and Wolfender $J-L$ (2021)

Isolation and Identification of Isocoumarin Derivatives With Specific Inhibitory Activity Against Wnt Pathway and Metabolome Characterization of

Lasiodiplodia venezuelensis.

Front. Chem. 9:664489.

doi: $10.3389 /$ fchem.2021.664489
Léonie Pellissier $^{1,2 *}$, Alexey Koval ${ }^{3}$, Laurence Marcourt ${ }^{1,2}$, Emerson Ferreira Queiroz ${ }^{1,2}$, Nicole Lecoultre ${ }^{4}$, Sara Leoni ${ }^{5}$, Luis-Manuel Quiros-Guerrero ${ }^{1,2}$, Morgane Barthélémy ${ }^{6}$, Bastiaan L. Duivelshof ${ }^{1,2}$, Davy Guillarme ${ }^{1,2}$, Sébastien Tardy ${ }^{1,2}$, Véronique Eparvier ${ }^{6}$, Karl Perron ${ }^{2,5}$, Jérôme Chave ${ }^{7}$, Didier Stien ${ }^{8}$, Katia Gindro ${ }^{4}$, Vladimir Katanaev ${ }^{3,9}$ and Jean-Luc Wolfender ${ }^{1,2 *}$

${ }^{1}$ School of Pharmaceutical Sciences, University of Geneva, CMU, Geneva, Switzerland, ${ }^{2}$ Institute of Pharmaceutical Sciences of Western Switzerland, University of Geneva, CMU, Geneva, Switzerland, ${ }^{3}$ Department of Cell Physiology and Metabolism, Translational Research Centre in Oncohaematology, Faculty of Medicine, University of Geneva, CMU, Geneva, Switzerland, ${ }^{4}$ Mycology Group, Research Department Plant Protection, Agroscope, Nyon, Switzerland, ${ }^{5}$ Microbiology Unit, Department of Botany and Plant Biology, University of Geneva, Geneva, Switzerland, ${ }^{6}$ Université Paris-Saclay, CNRS, Institut de Chimie des Substances Naturelles, Gif-sur-Yvette, France, ${ }^{7}$ CNRS, Biological Diversity and Evolution (UMR 5174), Toulouse, France,

${ }^{8}$ Sorbonne Université, CNRS, Laboratoire de Biodiversité et Biotechnologie Microbiennes, LBBM, Observatoire Océanologique, Banyuls-Sur-Mer, France, ${ }^{9}$ School of Biomedicine, Far Eastern Federal University, Vladivostok, Russia

The Wnt signaling pathway controls multiple events during embryonic development of multicellular animals and is carcinogenic when aberrantly activated in adults. Breast cancers are dependent on Wnt pathway overactivation mostly through dysregulation of pathway component protein expression, which necessitates the search for therapeutically relevant compounds targeting them. Highly diverse microorganisms as endophytes represent an underexplored field in the therapeutic natural products research. In the present work, the objective was to explore the chemical diversity and presence of selective Wnt inhibitors within a unique collection of fungi isolated as foliar endophytes from the longlived tropical palm Astrocaryum sciophilum. The fungi were cultured, extracted with ethyl acetate, and screened for their effects on the Wnt pathway and cell proliferation. The endophytic strain Lasiodiplodia venezuelensis was prioritized for scaled-up fractionation based on its selective activity. Application of geometric transfer from analytical HPLC conditions to semi-preparative scale and use of dry load sample introduction enabled the isolation of 15 pure compounds in a single step. Among the molecules identified, five are original natural products described for the first time, and six are new to this species. An active fraction obtained by semi-preparative HPLC was re-purified by UHPLC-PDA using a $1.7 \mu \mathrm{m}$ phenyl column. 75 injections of $8 \mu \mathrm{g}$ were necessary to obtain sufficient amounts of each compound for structure elucidation and bioassays. Using this original approach, in addition to the two major compounds, a third minor compound identified as (R)-(-)-5- 
hydroxymellein (18) was obtained, which was found to be responsible for the significant Wnt inhibition activity recorded. Further studies of this compound and its structural analogs showed that only 18 acts in a highly specific manner, with no acute cytotoxicity. This compound is notably selective for upstream components of the Wnt pathway and is able to inhibit the proliferation of three triple negative breast cancer cell lines. In addition to the discovery of Wnt inhibitors of interest, this study contributes to better characterize the biosynthetic potential of $L$. venezuelensis.

\section{Keywords: natural product, Wnt pathway inhibitors, anticancer, Lasiodiplodia venezuelensis, endophytic fungi, bio-} guided fractionation, isocoumarins, molecular networking

\section{INTRODUCTION}

The ever-increasing threat of cancer is one of the greatest challenges of modern medicine (Kunnumakkara et al., 2019). The current paradigm in anticancer drug development is that of targeted therapies, i.e., agents specifically targeting highly specific cancer pathways and components, thus minimizing toxic effects on healthy tissues (Ke and Shen, 2017).

While higher plants and soil microbes are being extensively explored as a source of new bioactive chemical entities, exploring uncommon microbial communities may increase the chances of finding such compounds (Zhu et al., 2012). In that respect, efforts have been recently turned towards the rarely encountered microorganisms inhabiting the tissues of higher plants, notably, bacteria, and fungi called endophytes (Stone et al., 2000). Endophytes are described as a fascinating group of microorganisms that reside in living plant tissues (beneath the epidermal cell layer) during a considerable part of their life cycle, without causing any symptoms (Petrini et al., 1991; Schulz et al., 2006). They occupy millions of unique biological niches, growing in biodiverse environments; almost all plant species studied until now have been found to host at least one to hundreds of endophytes (Arnold et al., 2000). Those microorganisms are thus considered as an underexploited reservoir of genetic and chemical diversity and novelty (Schulz et al., 2002). In a coevolutionary perspective, the host plant provides nutrition and structural protection to the endophytes, which in return help enhance the fitness and resistance of the host to adversity by producing functional secondary metabolites (Zhang et al., 2006; Martin et al., 2017). According to Tan et al., they possess a resistance mechanism to overcome pathogenic invasion and are considered unmatchable "chemical synthesizers" acting as producers of a wide range of pharmacologically active substances (Tan and Zou, 2001). Their residency in the host plant for a substantial period prompts a constant chemical innovation with potentially reduced toxicity towards the host cells, notably eukaryotic cells, making them a unique resource notably for discovering anticancer molecules (Omeje et al., 2017). Following the discovery that the Food and Drug Administration approved anticancer agent Taxol, originally isolated from Taxus brevifolia, was also produced by endophytic fungi such as Taxomyces andreanae, numerous endophytes have been found to be producers of potent anticancer agents (Stierle et al., 1995; Kusari et al., 2009).
The Wnt pathway is an intracellular signal transduction cascade that is activated in a highly specific and orchestrated manner during the embryonic development of multicellular animal organisms, from sponges to humans (Holstein, 2012). In mammals, the pathway plays an additional important role in adult tissue homeostasis through controlling the tissue regeneration and renewal (Ring et al., 2014; Steinhart and Angers, 2018). This multitude of activities controlled by the activated Wnt pathway provides a significant benefit for the tumor cells of different cancer types, most notably triplenegative breast cancer (TNBC), colorectal and hepatocellular carcinomas, lung, and ovarian cancers, by endorsing their proliferation, migration, and metastasis formation (Zhan et al., 2017).

The most prominent and well-described role in cancer belongs to the so-called canonical branch of Wnt signaling. In this branch, the signals emanating from the binding of secreted Wnt proteins to their cognate GPCRs Frizzled receptors are transduced intracellularly through $G$ proteins and the phosphoprotein Dishevelled (Dvl) (Koval and Katanaev, 2011). This action results in inhibition of the so-called "destruction complex" - an assembly of proteins Axin, APC, and GSK3beta, which in the absence of signal efficiently phosphorylates the cytoplasmic pool of betacatenin, mediating its proteasomal degradation. Upon the arrival of the Wnt signal, the destruction complex becomes inactive and beta-catenin accumulates in the cytoplasm and subsequently penetrates the nucleus, where it serves as a transcriptional co-factor to the TCF/LEF family of the proteins (Koval et al., 2011). The transcriptional program initiated this way by Wnt ligands includes several hundred genes and provides a major boost for cell proliferation (Koval and Katanaev, 2018).

However, direct targeting of the Wnt pathway by acting on its most widespread components has detrimental effects on the Wnt-dependent healthy tissues resulting in poorly manageable adverse effects and failure to advance in clinical trials (Shaw et al., 2019a). More selective Wnt-targeting agents are thus required, targeting only the components essential for cancers (Blagodatski et al., 2014; Kahn, 2014). Such components are naturally more abundant in the upstream parts of the pathway, with the diversity of the Wnt ligand and Frizzled receptor orthologs differentially expressed in the tissues being particularly attractive (Shaw et al., 2019b). 
In the search for new natural products targeting the Wnt pathway, we sought to investigate cultivated communities of endophytic fungi in model plants known for their long-life cycle and possibly hosting steady microbial communities over many years.

In this context, we focused on a collection of foliar endophytic fungi isolated from the host model Astrocaryum sciophilum (Miq.) Pulle. A. sciophilum is a solitary, understory palm endemic to the northeast region of the Amazon basin (Amapá and Pará states of Brazil, French Guiana, Guyana, Suriname) (Kahn, 2008). Its remarkable maturation age of around 170 years makes it a long-lived, resistant species, with leaves that can be up to 20 years old (Charles-Dominique et al., 2003). This suggests that endophytes residing in its leaves can persist for a considerable time and can be resistant to environmental menace. They might have developed antipathogens and cytotoxic metabolites involved in the longevity of the shoots and leaves of the palm (Arnold et al., 2003). Moreover, the highly competitive rainforest ecosystem makes the selection pressure intense, probably prompting microbes associated with a tropical host to produce potent secondary metabolites (Rosa et al., 2011).

Previous work on this plant model has shown, in another collection of endophytes, that it contained some cytotoxic and antimicrobial strains in which some bioactive compounds have been identified (Barthélemy et al., 2019; Donald et al., 2019; Barthélemy et al., 2020). In the present work, a collection of fungi isolated as cultivable endophyte strains from the leaves of $A$. sciophilum were cultured, extracted, and screened for their effects on cell proliferation and Wnt pathway inhibition. Among them, the endophytic strain Lasiodiplodia venezuelensis Burgess, Barber, and Mohali (Burgess et al., 2006) was prioritized for scaled-up fractionation for its selective activity and taxonomical originality.

The genus Lasiodiplodia belongs to the phylum Ascomycota, class Dothideomycetes, order Botryospheaeriales, and family Botryiosphaeriaceae (Robert et al., 2005). Members of this family, as the Lasiodiplodia spp., have been found on a large variety of plant hosts as important pathogens of several woody perennial plants, causing diseases as cankers, blights, and rots and dieback symptoms (Correia et al., 2016; Vieira et al., 2018; Li et al., 2019). They can also survive as saprophytes and/or endophytes within seeds and living tissues, in a latent phase, not causing any symptoms (Smith et al., 1996). Lasiodiplodia species are common mostly in tropical and subtropical regions (De Wet et al., 2008). L. venezuelensis was first described by Burgess et al. in 2006 (Burgess et al., 2006) in the living wood tissues of Acacia mangium Willd. in Venezuela and later on by Urbez-Torres et al. from Pinus caribaea var. hondurensis Barret and Golfari (Úrbez-Torres et al., 2016). This species was also associated with a blue stain of wood in Venezuelan lumber yards (Mohali et al., 2017). Since they were re-isolated from asymptomatic wood and did not cause any lesions when re-inoculated, they are considered endophyte or latent pathogens. In comparison with other Lasiodiplodia spp., $L$. venezuelensis seems to have a restricted distribution since it has not been reported elsewhere in the world to date (Mohali et al., 2017).
In the frame of the present study, the anti-Wnt metabolites are characterized, and detailed profiling of this strain is provided to document its metabolite composition.

\section{RESULTS AND DISCUSSION}

\section{Biological Activities of Fungal Extracts}

A collection of 15 strains isolated as cultivable endophytes from the leaves of A. sciophilum were cultured and extracted with ethyl acetate (EtOAc). The extracts were then partitioned with water (W). All extracts were screened for their effects on Wnt pathway inhibition. The specificity was controlled by analyzing general cytotoxicity. As a system to screen compounds for the potential anti-Wnt signaling activities, we used the BT-20 TNBC cells, stably transfected with the TopFlash reporter construct, responding by luciferase expression to stimulation with purified Wnt3a (Koval et al., 2014). EtOAc and W extracts of fungi were tested at different concentrations in this assay. Only the extracts exhibiting either no cytotoxicity or at least a cytotoxic $\mathrm{IC}_{50} 3$-fold higher than the Wnt-specific one were considered as those with selective Wnt inhibition. Among them, the EtOAc extract of the strain A02 identified as Lasiodiplodia venezuelensis exhibited a clear specific inhibitory activity (Wnt IC $_{50}$ of $180 \pm$ $56 \mu \mathrm{g} / \mathrm{ml}$ ) and low cytotoxicity (Renilla inhibition $\mathrm{IC}_{50}>500 \mu \mathrm{g} /$ $\mathrm{ml}$ (estimated)). Based on the bioactivity results and a preliminary metabolite profiling revealing an interesting composition (see section Deep Metabolome Analysis), the A02 strain was prioritized and cultivated on a large scale $(10014 \mathrm{~cm}$ diameter Petri dishes) and extracted with the same procedure as for the screening. The large-scale EtOAc extract (A02Et) was then tested in an independent series of measurements and confirmed the anti-Wnt activity observed on a small scale ( $\mathrm{IC}_{50}$ of $27 \pm 6 \mu \mathrm{g}$ / $\mathrm{ml}$, cytotoxic $\mathrm{IC}_{50}$ of $\left.143 \pm 9 \mu \mathrm{g} / \mathrm{ml}\right)$.

\section{Bioactivity-Guided Fractionation and Isolation}

A first chemical profile of the bioactive A02Et extract by HPLCPDA-ELSD revealed the presence of a significant amount of lipophilic compounds as shown by ELSD. In order to rule out a possible interference of lipid compounds in the Wnt assay, the EtOAc extract was further simplified by liquid/liquid partitioning hexane/methanol: $\mathrm{H}_{2} \mathrm{O}$ (7:3). This process yielded an apolar hexane fraction $(\mathrm{A} 02 \mathrm{EtH})$ and an enriched hydroalcoholic fraction (A02EtM) (Supplementary Figure 1). The specific anti-Wnt activity was only exhibited by A02EtM extract, which was enriched in more polar secondary metabolites (Wnt $\mathrm{IC}_{50}$ of $13 \pm 3.5 \mu \mathrm{g} / \mathrm{ml}$; cytotoxic $\mathrm{IC}_{50}$ of $97 \pm 16 \mu \mathrm{g} / \mathrm{ml}$ ).

For efficient isolation of the active compounds, the reverse phase HPLC-PDA-ELSD conditions were optimized in order to obtain an efficient separation (Figure 1A). Those conditions were transferred to semi-preparative HPLC using a geometric gradient transfer method to obtain similar chromatographic selectivity (Guillarme et al., 2008). In order to avoid loss of resolution, the extract was introduced by dry load, following a protocol recently developed in our laboratory (Queiroz et al., 2019). 


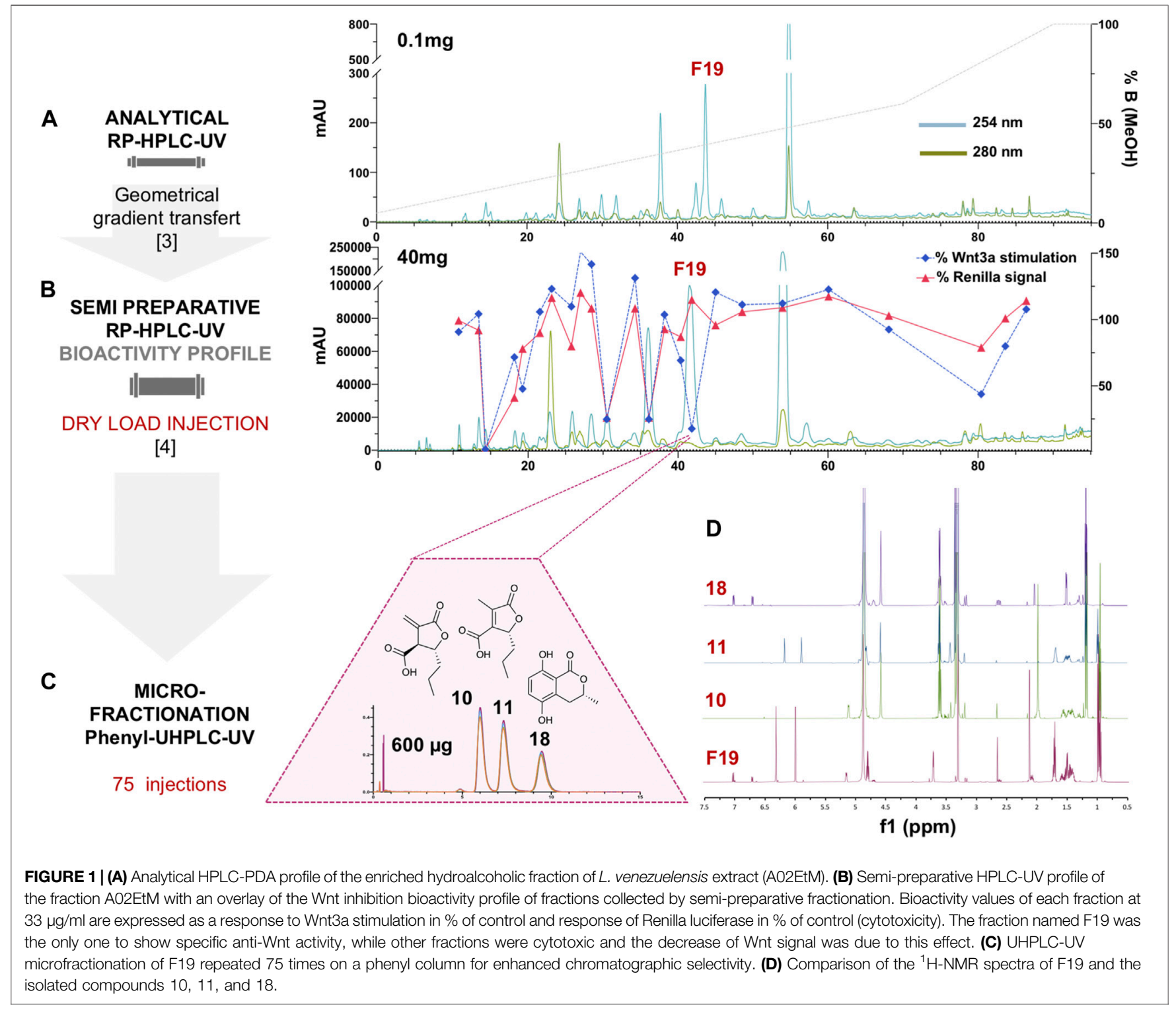

The high-resolution HPLC semi-preparative fractionation of the extract provided a good baseline separation of most compounds detected by UV (Figure 1B and Supplementary Figure 2). This efficient process yielded thirty-three fractions containing mainly single HPLC peaks that were directly submitted to the Wnt inhibition bioassays (Supplementary Figure 3). The results of the assay were displayed as a bioactivity profile (\% of control activity at $33 \mu \mathrm{g} / \mathrm{ml}$ ), which highlighted the chromatographic zone of activity (Figure 1B). The F19 fraction was the only one to show specific anti-Wnt activity, while other fractions were cytotoxic, with the decrease of the Wnt signal due to this effect. Fraction $\mathrm{F} 19 \mathrm{Wnt}^{\mathrm{IC}_{50}}$ was $15 \pm 3.9 \mu \mathrm{g} / \mathrm{ml}$, and cytotoxic $\mathrm{IC}_{50}$ was $>200 \mu \mathrm{g} / \mathrm{ml}$.

The A02EtM and the F19 fraction were profiled by UHPLCPDA-HRMS/MS using data-dependent acquisition mode followed by metabolite annotation to estimate its chemical composition. The detailed procedure for metabolite annotation is described in the following section (Deep Metabolome Analysis).

A careful analysis of the HRMS and HRMS/MS spectra of the active fraction F19 in the chemical profile of the extract revealed that it contained molecular ions corresponding to two distinct molecules (Supplementary Figure 4). The first feature at $\mathrm{m} / \mathrm{z}$ $185.0809[\mathrm{M}+\mathrm{H}]^{+}$and $183.0661[\mathrm{M}-\mathrm{H}]^{-}$indicated a compound with a molecular formula of $\mathrm{C}_{9} \mathrm{H}_{12} \mathrm{O}_{4}$ (calcd. for $\mathrm{C}_{9} \mathrm{H}_{13} \mathrm{O}_{4}{ }^{+}, 185.0808, \Delta \mathrm{ppm}=0.30$ and $\mathrm{C}_{9} \mathrm{H}_{11} \mathrm{O}_{4}{ }^{-}, 183.0663$, $\Delta \mathrm{ppm}=1.09)$, corresponding to 4 degrees of unsaturation. In MS1 and MS/MS, this ion was dereplicated as decumbic acid, already isolated from Lasiodiplodia theobromae ( $\mathrm{He}$ et al., 2004). The second ion at $m / z$ 195.0652 $[\mathrm{M}+\mathrm{H}]^{+}$and $193.0505[\mathrm{M}-\mathrm{H}]^{-}$indicated a compound with a molecular formula of $\mathrm{C}_{10} \mathrm{H}_{10} \mathrm{O}_{4}$ (calcd. for $\mathrm{C}_{10} \mathrm{H}_{11} \mathrm{O}_{4}{ }^{+}$, 195.0652, $\Delta \mathrm{ppm}$ $=0.00$ and $\left.\mathrm{C}_{10} \mathrm{H}_{9} \mathrm{O}_{4}{ }^{-}, 193.0506, \Delta \mathrm{ppm}=0.52\right)$, corresponding to 6 degrees of unsaturation. In MS1, this ion was dereplicated as 
3,4-dihydro-4,8-dihydroxy-3-methyl-1H-2-benzopyran-1-one (4-hydroxymellein), also isolated from Lasiodiplodia theobromae (Salvatore et al., 2020). MS/MS dereplication against the DNP-ISDB, an in-house database containing the in silico fragmentation spectra of all the compounds present in the Dictionary of Natural Products (DNP), annotated the compound corresponding to this feature as 3,4-dihydro-3,8dihydroxy-3-methyl-1H-2-benzopyran-1-one, which differed in the hydroxylation pattern. This indicated that this feature was an hydroxymellein derivative, but its exact structure could not be asserted at this level.

This fraction was also profiled by NMR, which revealed that it was composed of two isomers along with a minor compound with a ratio of $1(40 \%) / 1.3(50 \%) / 0.4(10 \%)$ moles. The main signals in the NMR spectrum corresponded to decumbic acid, as suggested by the MS/MS annotation. However, signals at $\delta_{\mathrm{H}} 6.32$ and 6.00 $(J=2.8 \mathrm{~Hz})$ corresponding to an exocyclic double bond that replaced the methyl at $\delta_{\mathrm{H}} 2.13$ of the decumbic acid (11), and an additional methine at $\delta_{\mathrm{H}} 3.72(\mathrm{dt}, J=5.6,2.8 \mathrm{~Hz})$ revealed that an isomer of decumbic acid with a close structure was also present (10). The minor signals in this fraction seem to correspond partly to the hydroxymellein derivative (18) dereplicated by MS/MS, but a full de novo identification could not be made at this stage (Figure 1D).

In order to identify which metabolite(s) was responsible for the Wnt inhibition, careful purification was needed since none of them was described as an anti-Wnt inhibitor.

Several analytical HPLC conditions were tested but did not enable a baseline separation of the three constituents. Further UHPLC-PDA profiling of this fraction using an analytical phenyl column packed with $1.7 \mu \mathrm{m}$ silica beads finally yielded an efficient separation of the three constituents (Figure 1C). This challenging separation could not be upscaled and a microfractionation strategy had to be devised directly on the UHPLC platform at the analytical scale.

Since the loading capacity of the UHPLC column was very limited, a series of 75 injections of $8 \mu \mathrm{g}$ each was performed (Figure 1C). All separations exhibited well-aligned profiles, allowing efficient multiple collections of each of the three peaks (Supplementary Figure 5). This led to the purification of the three compounds of fraction F19. The two major isomers were obtained at 94 and $83 \mu \mathrm{g}$, and the minor constituent was obtained at $29 \mu \mathrm{g}$ (Figures 1C,D). Since only minute amounts could be obtained at the UHPLC scale, they were quantified during NMR analysis for a precise concentration assignment for the bioassays.

The two major compounds were confirmed to be two lactone derivatives, $(3 S, 4 R)$-3-carboxy-2-methylene-heptan-4-olide (10), a toxin responsible for the decay of tropical fruit, and its inactive derivative, decumbic acid (11), isolated from $L$. theobromae $(\mathrm{He}$ et al., 2004). The third minor compound was finally identified as (R)-(-)-5-hydroxymellein (18). Melleins are a subgroup of 3,4dihydrocoumarins that belong to the subgroup of isocoumarins, a well-known polyketides family. Such derivatives are produced by bacteria, fungi, higher plants, insects, lichens, and marine sponges, the most important source of mellein being the fungi. They have shown a wide range of biological activities
(Reveglia et al., 2020). They were mainly reported as phytotoxins produced by Botryosphaeriaceae species (Cimmino et al., 2017; Reveglia et al., 2019). (-)-(R)-Mellein $(3 R, 4 S)$ and $(3 R, 4 R)-4$-hydroxymellein and (3R)-5hydroxymellein have already been isolated from Lasiodiplodia sp. 5-Hydroxymellein has been already isolated from Lasiodiplodia theobromae but never reported in $L$. venezuelensis (Salvatore et al., 2020). It has also been isolated from the endophytic fungus Aspergillus flocculus, inhibiting the growth of K562 cancer cell lines (Tawfike et al., 2019). The NMR analysis of 18 unambiguously confirmed its hydroxylation and configuration pattern, which could not be inferred by dereplication.

Because of the small amount obtained, we took advantage of the NMR analysis to precisely quantify each of the three compounds in view of the bioassays. Those final bioassays clearly demonstrated that the third minor compound $(R)$ (-)-5-hydroxymellein (18) was responsible for the significant Wnt inhibition activity of the fraction $\mathrm{F} 19$, with a Wnt $\mathrm{IC}_{50}$ of $6.7 \pm 1.2 \mu \mathrm{g} / \mathrm{ml}(58 \pm 16 \mu \mathrm{M}) \quad\left(\right.$ cytotoxic $\mathrm{IC}_{50}>20 \mu \mathrm{g} / \mathrm{ml}$ $(>500 \mu \mathrm{M}))$ (Figure 2A).

\section{Chemical Characterization of Other Secondary Metabolites From the Hydroalcoholic Extract (A02EtM)}

The first chemical profiling of the extract by UHPLC-HRMS/MS indicated a potentially interesting chemical composition of the ethyl acetate extract of L. venezuelensis. Moreover, the metabolome of this particular species was not described in the literature. In order to document the composition of this strain and understand its chemodiversity, we took advantage of having the UHPLCHRMS/MS metabolite profiling and the NMR analysis of the highresolution semi-preparative HPLC fractions to combine this information for a deep metabolome characterization. Furthermore, we highlighted a cluster of potential analogs of the active 5-hydroxymellein 18 and exploited the possibility of isolating them to further assess any structure-activity relationship (see section Deep Metabolome Analysis).

\section{De Novo Structure Identification of All Pure Fractions by NMR}

From the 33 fractions obtained from semi-preparative HPLC semi-preparative purification, fifteen pure compounds (1-15) were successfully isolated in a single step (Figure 3). Ten compounds were identified by comparison with the literature

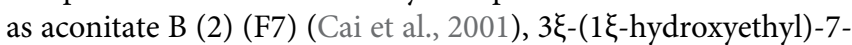
hydroxy-1-isobenzofuranone (mixture of two isomers) (5) (F10) (Rahman and Gray, 2005), (+)-(3R,4S)-4,5-dihydroxymellein (7) (F13) (Meepagala et al., 2018), (-)-(3R,4R)-4-hydroxymellein (8) (F14) (Djoukeng et al., 2009), (-)-(3R,4S)-4-hydroxymellein (9) (F16) (Cimmino et al., 2017), decumbic acid B (12) (F20) (Zhou et al., 2016), (-)-(R)-mellein (13) (F22) (Djoukeng et al., 2009), (2R)-butylitaconic acid (14) (F24) (Nakahashi et al., 2009), the enantiomers of dihydroxynaphtalene derivatives CJ-12,372 (15) (F26) (Sakemi et al., 1995), and palmarumycin EG1 (16) (F29) 


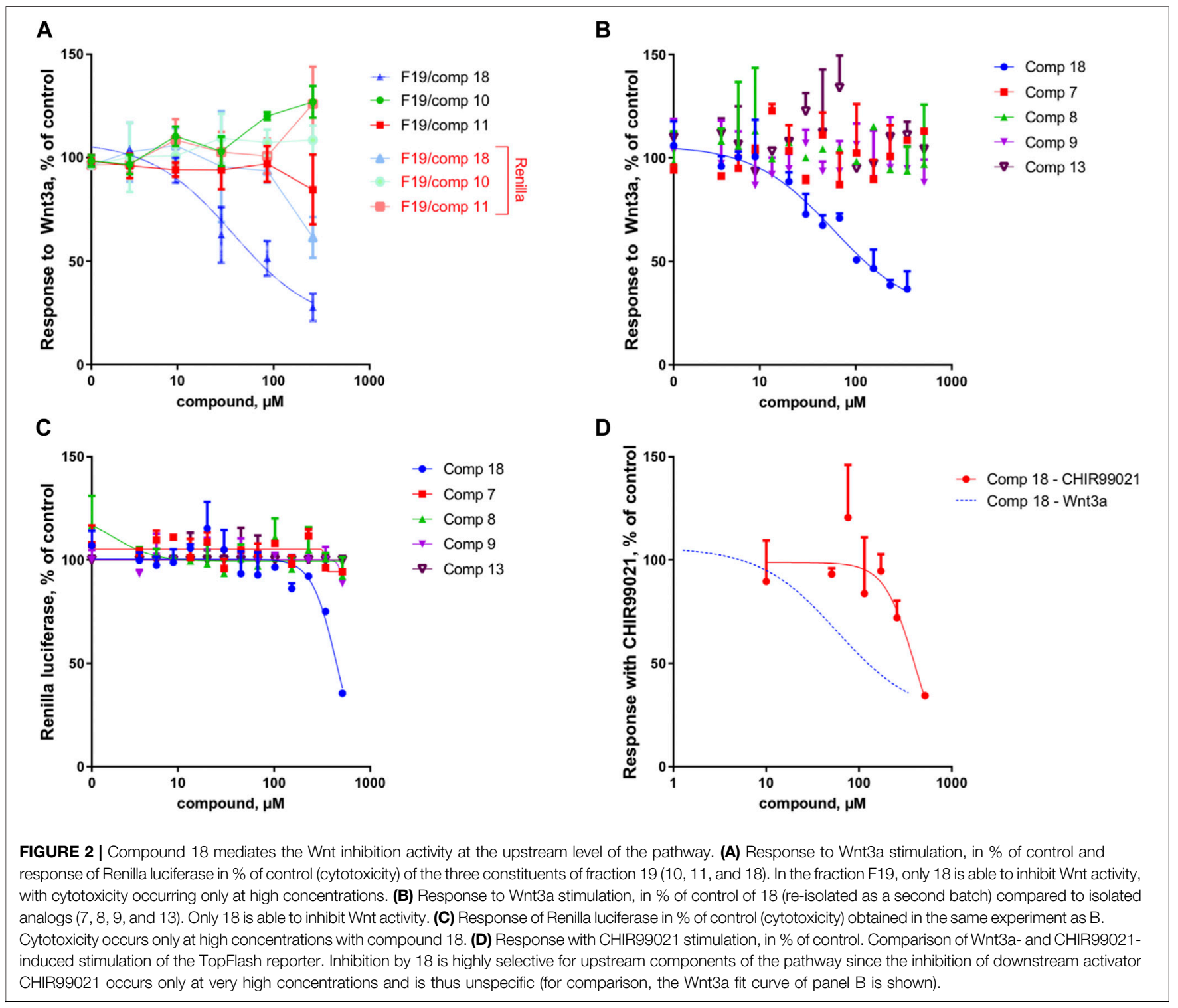

(Macías-Rubalcava et al., 2014). All compounds were described as fungal metabolites, but only compounds 8,9 , and 13 were already described in the Botryosphaeriaceae family. In addition, five other compounds are original natural products, and their full de novo structure identification is described hereafter.

Compound 1 (F6) was isolated as an oil. The ESI(+)-HRMS experiment indicated a molecular formula of $\mathrm{C}_{19} \mathrm{H}_{15} \mathrm{NO}_{4}$ with a $m / z$ of $214.1071[\mathrm{M}+\mathrm{H}]^{+}$(calcd. for $\mathrm{C}_{10} \mathrm{H}_{16} \mathrm{NO}_{4}{ }^{+}, 214.1074$, $\Delta \mathrm{ppm}=1.40$ ), which corresponded to 4 degrees of unsaturation. Analysis of the ${ }^{1} \mathrm{H},{ }^{13} \mathrm{C}$ and HSQC NMR data of 1 indicated the presence of a dihydropyran scaffold consisting of two olefinic carbons at $\delta_{\mathrm{C}} 135.0(\mathrm{C}-3)$ and $123.3(\mathrm{C}-4)$ and three oximethines at $\delta_{\mathrm{C}} 80.6(\mathrm{C}-2), 71.5(\mathrm{C}-5), 66.2(\mathrm{C}-6)$. In addition to these signals, a methyl group at $\delta_{\mathrm{H}} 1.19(3 \mathrm{H}, \mathrm{d}, J=6.4 \mathrm{~Hz}, \mathrm{H}-8)$, an oximethine at $\delta_{\mathrm{H}} 3.71(1 \mathrm{H}, \mathrm{qd}, J=6.4,5.8 \mathrm{~Hz}, \mathrm{H}-7)$, two olefinic protons at $\delta_{\mathrm{H}} 7.00\left(1 \mathrm{H}, \mathrm{dd}, J=9.8,5.8 \mathrm{~Hz}, \mathrm{H}-1^{\prime}\right)$ and $\delta_{\mathrm{H}} 6.18(1 \mathrm{H}$, $\left.\mathrm{d}, J=9.8 \mathrm{~Hz}, \mathrm{H}-2^{\prime}\right)$, and an ester carbonyl at $\delta_{\mathrm{C}} 165.4\left(\mathrm{C}-3^{\prime}\right)$ were observed. Sequential COSY correlations from $\mathrm{H}-6$ at $\delta_{\mathrm{H}} 4.17(1 \mathrm{H}$, $\mathrm{dd}, J=5.8,2.8 \mathrm{~Hz})$ to $\mathrm{H}-5\left(\delta_{\mathrm{H}} 4.74\right), \mathrm{H}-4\left(\delta_{\mathrm{H}} 6.10\right)$, and $\mathrm{H}-3\left(\delta_{\mathrm{H}}\right.$ 6.32) and $\mathrm{HMBC}$ correlations from the olefinic proton $\mathrm{H}-4$ at $\delta_{\mathrm{H}}$ $6.10(1 \mathrm{H}$, ddd, $J=10.4,5.2,2.3 \mathrm{~Hz})$ to $\mathrm{C}-2$ and $\mathrm{C}-6$ and from the oximethine proton $\mathrm{H}-6$ to $\mathrm{C}-5$ and $\mathrm{C}-2$ allowed defining a 3,6dihydro- $2 \mathrm{H}$-pyran-3-ol ring. The COSY correlations from $\mathrm{H}-1^{\prime}$ to $\mathrm{H}-2$ ' and $\mathrm{H}-6$ and $\mathrm{HMBC}$ correlations from $\mathrm{H}-1$ ' and $\mathrm{H}-2$ ' to the ester carbonyl C-3' positioned a propenamide side chain at $\mathrm{C}$ 6. The $9.8 \mathrm{~Hz}$ coupling constant of the set of olefinic protons $\mathrm{H}-1^{\prime}$ and $\mathrm{H}-2$ ' demonstrated the cis configuration of the double bond on this side chain. Correlation from the methyl protons $\mathrm{H}-8$ to the oximethine C-7 $\left(\delta_{\mathrm{C}} 69.9\right)$ and C-2 located a 1-hydroxyethyl group in C-2. Further, COSY correlations from $\mathrm{H}-7$ to $\mathrm{H}-8$ and $\mathrm{H}-2$ supported the position of this second side chain. The ROESY correlations from H-6 to H-5 and H-2 and the small coupling constant between $\mathrm{H}-5$ and $\mathrm{H}-6(J=2.8 \mathrm{~Hz})$ indicated the relative configuration of the 3,6-dihydro- $2 \mathrm{H}$-pyran-3-ol ring 


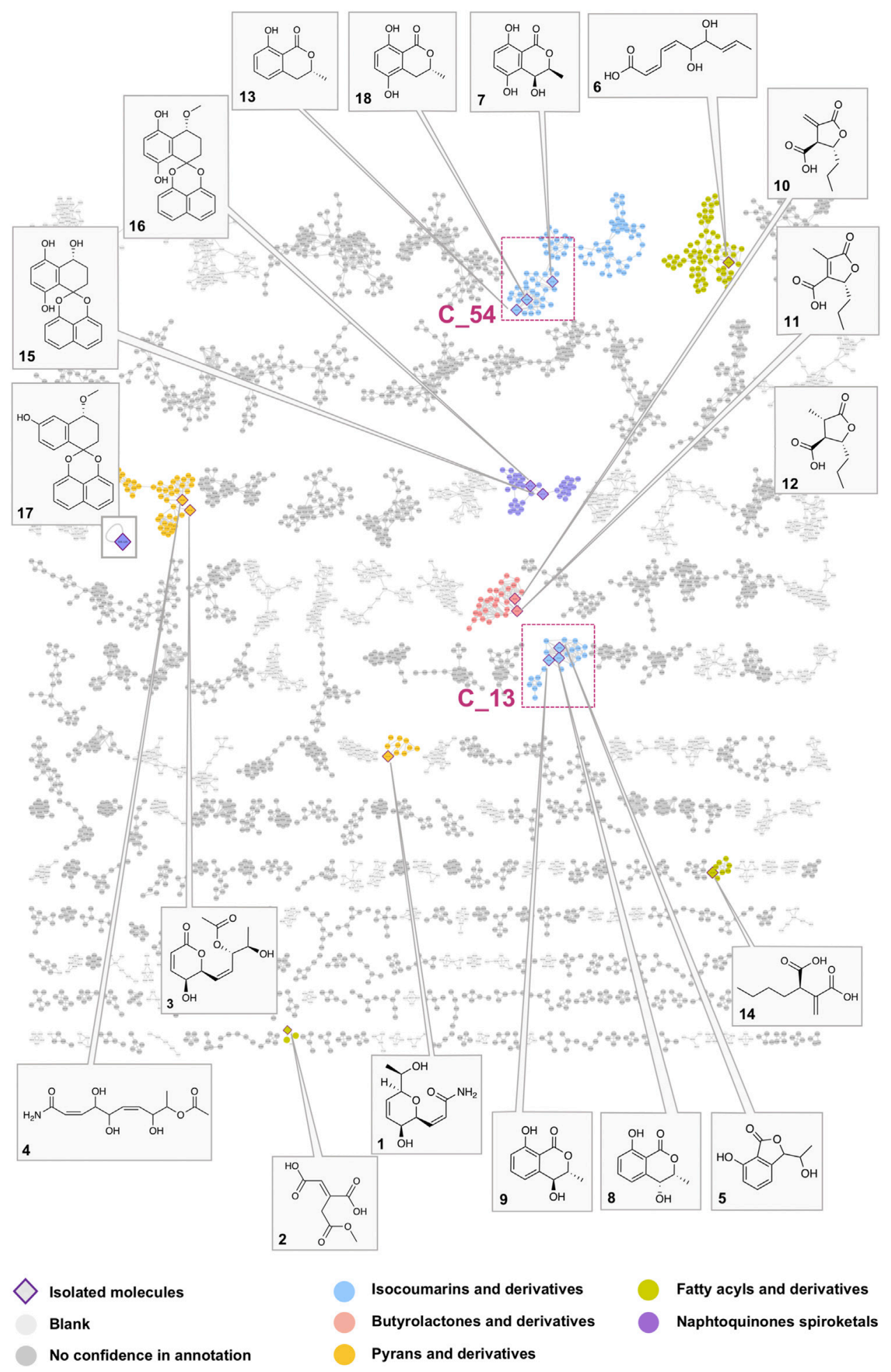

FIGURE 3 | Global molecular network of the A02EtM extract and the 33 semi-preparative fractions with attribution of the nodes of all pure compounds isolated from the HPLC semi-preparative purification and their corresponding clusters. Colors of the nodes correspond to chemical families tentatively assigned to the clusters through the use of a consensus structural annotation at different Classyfire taxa levels. Clusters C_54 and C_13, highlighted with red squares, are annotated as benzopyran derivatives (C_54 with the active compound 18 and isolated analogs 7 and 13) (C_13 with compounds 5, eight and 9). A detailed view of the selected clusters is displayed in Figure 6. 

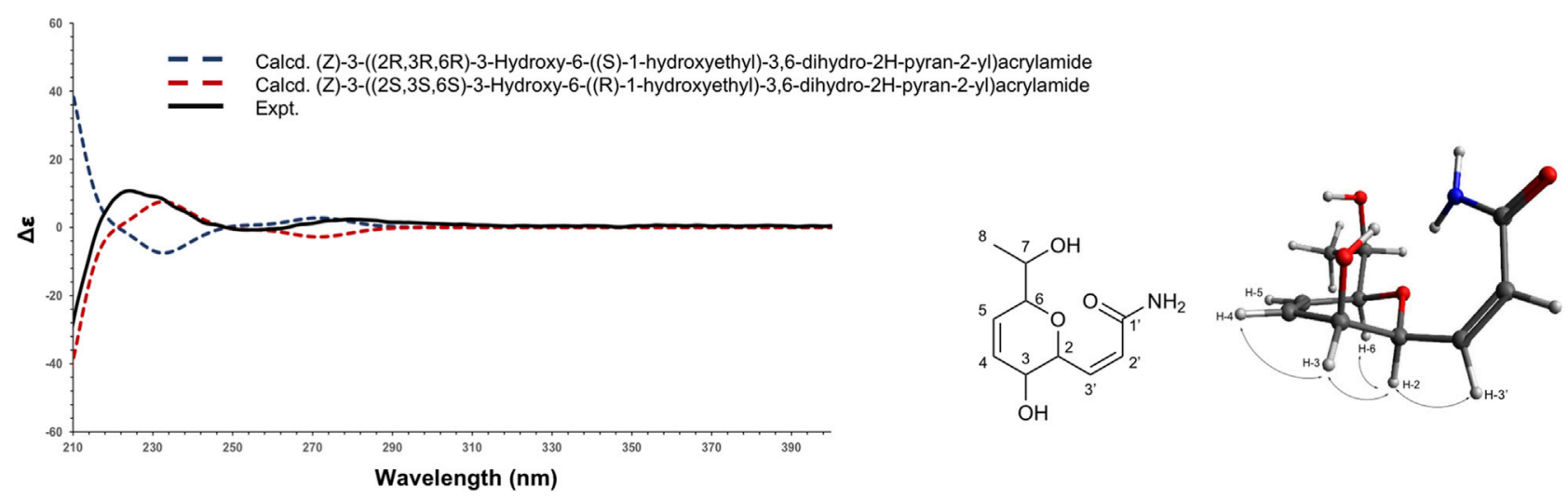

FIGURE 4 | Experimental (black) and TFT-TD-calculated ECD spectra of the two enantiomers (2R,3R,6R), ((S)-1-hydroxyethyl) (blue), and (2S,3S,6S), ((R)-1hydroxyethyl) (red) of compound 1.

(Supplementary Figures 6-11). To establish the absolute configuration of compound 1, the ECD spectrum was calculated based on the relative configuration proposed by NMR and compared to the experimental data (Figure 4). After the comparison, three stereocenters of the 6,6-dihydro$2 \mathrm{H}$-pyran-3-ol were all deduced as $(R)$ configurations. To define the absolute configuration of C-7, the S-MTPA and R-MTPA ester derivatives were synthesized from the $(R)$ - and $(S)$ a-methoxy-a-trifluoromethylphenylacetyl chloride, respectively (Supplementary Figure 12) (Hoye et al., 2007). The downfield shift of the methyl H-8 and the upfield shift of $\mathrm{H}-2$ in the $R$-MTPA ester relative to the S-MTPA ester were consistent with a C-7 $(R)$ configuration (Supplementary Figures 13-18). After comparison, 1 was assigned as the new molecule (2Z)-3 $[(1 R, 2 R, 5 R)$-2-hydroxy-5[(1R)-1-hydroxyethyl $]$ cyclohex-3-en-1yl]prop-2-enamide.

Compound 3 (F8) was isolated as an oil. The ESI(+)-HRMS experiment indicated a molecular formula of $\mathrm{C}_{12} \mathrm{H}_{16} \mathrm{O}_{6}$ with a $\mathrm{m} /$ $z$ of $257.1020[\mathrm{M}+\mathrm{H}]^{+}$(calcd. for $\mathrm{C}_{12} \mathrm{H}_{17} \mathrm{O}_{6}{ }^{+}, 257.1020, \Delta \mathrm{ppm}=$ 0.00 ), which corresponded to 5 degrees of unsaturation. Analysis of the ${ }^{1} \mathrm{H}-\mathrm{NMR}$ and HSQC data of 3 , as this was the case for 1 indicated the presence of a dihydropyranone scaffold consisting of two olefinic carbons at $\delta_{\mathrm{C}} 121.1(\mathrm{C}-3)$ and 146.1 (C-4) two oximethines carbons at $\delta_{\mathrm{C}} 60.8(\mathrm{C}-5)$ and 76.1 (C-6). In addition to these signals, two olefinic protons at $\delta_{\mathrm{H}} 5.90(1 \mathrm{H}, \mathrm{t}, J=11.1,9.2$ $\left.\mathrm{Hz}, \mathrm{H}-1^{\prime}\right)$ and $\delta_{\mathrm{H}} 5.71\left(1 \mathrm{H}, \mathrm{ddd}, J=11.1,9.3,1.1 \mathrm{~Hz}, \mathrm{H}-2^{\prime}\right)$, two oximethines protons at $\delta_{\mathrm{H}} 5.29\left(1 \mathrm{H}, \mathrm{dd}, J=9.3,3.1 \mathrm{~Hz}, \mathrm{H}-3^{\prime}\right)$ and at $\delta_{\mathrm{H}} 3.77\left(1 \mathrm{H}, \mathrm{qdd}, J=6.4,5.3,3.1 \mathrm{~Hz}, \mathrm{H}-4^{\prime}\right)$, two methyl groups at $\delta_{\mathrm{H}} 1.05\left(3 \mathrm{H}, \mathrm{d}, J=6.4 \mathrm{~Hz}, \mathrm{H}-5^{\prime}\right)$ and $\delta_{\mathrm{H}} 2.01\left(3 \mathrm{H}, \mathrm{s}, \mathrm{H}-7^{\prime}\right)$, and two protons from hydroxy groups at $\delta_{\mathrm{H}} 5.60(1 \mathrm{H}, \mathrm{d}, J=7.1 \mathrm{~Hz}$, $\mathrm{OH} 5)$ and at $\delta_{\mathrm{H}} 4.87\left(1 \mathrm{H}, \mathrm{d}, J=5.3 \mathrm{~Hz}, \mathrm{OH} 4{ }^{\prime}\right)$. Analysis of the $\mathrm{HMBC}$ spectrum revealed correlations from the olefinic proton $\mathrm{H}-3$ to the ester carbonyl C-2 at $\delta_{\mathrm{C}} 162.9$ and to C-5 and from the second olefinic proton $\mathrm{H}-4$ to $\mathrm{C}-5, \mathrm{C}-6$, and C-2. Furthermore, COSY correlations between the olefinic protons $\mathrm{H}-3$ and $\mathrm{H}-4$ and from $\mathrm{H}-4$ to $\mathrm{H}-5$ defined the dihydropyranone moiety. COSY correlation from $\mathrm{H}-5$ to the hydroxyl group at $\delta_{\mathrm{H}} 5.60$ placed the first hydroxy group in position C-5. Sequential COSY correlations from H-6 to H-1', H-2', and H-3' and HMBC correlations from the methyl $\mathrm{H}-5^{\prime}$ to $\mathrm{C}-4$ ' $\left(\delta_{\mathrm{C}} 66.8\right)$ and $\mathrm{C}-3^{\prime}$ $\left(\delta_{\mathrm{C}} 73.4\right)$ positioned the side chain at C-6. COSY correlation between $\mathrm{H}-4$ ' and the hydroxyl group at $\delta_{\mathrm{H}} 4.87$ placed the second hydroxy group in position C-4'. HMBC correlations from the ester carbonyl at $\delta_{\mathrm{C}} 169.5$ to H-3' and to the methyl at $\delta_{\mathrm{H}} 2.01$ positioned an acetate in C-3'. The $11.1 \mathrm{~Hz}$ coupling constant of the set of olefinic protons $\mathrm{H}-1$ ' and $\mathrm{H}-2$ ' demonstrated the cis configuration of the double bond on the side chain. The ROESY correlation between H-5 and H-6 and the $J_{5,6}$ value of $2.0 \mathrm{~Hz}$ positioned the propenamide side chain at C-6 in a pseudoequatorial orientation and the hydroxy group at C-5 in axial orientation. Moreover, the positive Cotton effect in the circular dichroism curve ( $\Delta \varepsilon$ 260-290 nm) was correlated with the C-6 $(S)$ configuration as described for substituted dihydro- $\alpha$-pyrones in the literature (Pereda-Miranda et al., 1993). The small coupling constant between $\mathrm{H}-3^{\prime}$ and $\mathrm{H}-4^{\prime}\left(J_{3^{\prime}, 4^{\prime}}=3.1 \mathrm{~Hz}\right)$ and the ROESY correlations from $\mathrm{H}-3^{\prime}$ to $\mathrm{H}-4^{\prime}$ and $\mathrm{OH} 4^{\prime}$ and from $\mathrm{H}-4$ ' to $\mathrm{H}-2^{\prime}$ indicated a $3^{\prime} S, 4^{\prime} R$ or $3^{\prime} R, 4^{\prime} S$ configuration of the side chain (Supplementary Figures 25-29).

To establish the absolute configuration of 3 , the ECD spectrum was calculated based on the relative configuration proposed by NMR and compared to the experimental data (Figure 5). After the comparison, 3 was assigned as the new molecule $(1 Z, 3 S, 4 R)$ 4-hydroxy-1-[(2S,3S)-3-hydroxy-6-oxo-3,6-dihydro-2H-pyran2-yl]pent-1-en-3-yl acetate.

Molecules containing such an $\alpha, \beta$-unsaturated lactone ring are commonly occurring natural products from various biological sources. Compounds with such a structural pattern are known to exhibit a wide range of biological activities. Representative examples are the cytotoxic and antibacterial pectinolides isolated from the plant species Hyptis pectinata (Vogt et al., 2009). Other examples include pironetin isolated from Streptomyces sp. NK10958, antimitotic and inhibitor of plant growth (Zhou et al., 2017), and asperlin isolated from the marine fungus Aspergillus versicolor (Matsumoto and Nago, 1994). To date, apart from isocoumarin derivatives, two $2 \mathrm{H}$-pyran-2-one derivatives, (R)-2-octeno- $\delta$-lactone (lasiolactone) and (R)-2deceno- $\delta$-lactone (massoialactone), have been isolated from $L$. theobromae (Martínez-Luis et al., 2008). 


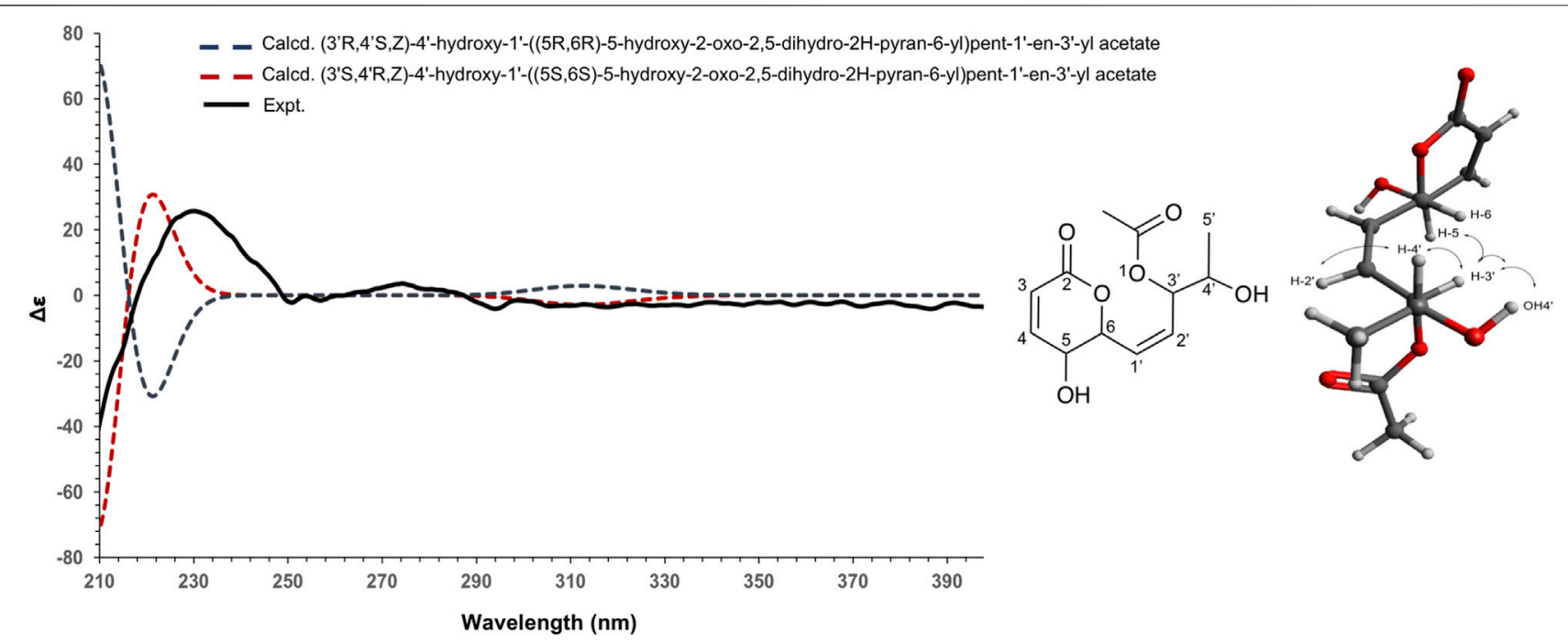

FIGURE 5 | Experimental (black) and TFT-TD-calculated ECD spectra of the two enantiomers (3'R,4'S,Z), (5R,6R) (blue), and (3'S,4'R,Z), (5S, 6S) (red) of compound 3 .

Compound 4 (F9) was isolated as an oil. The ESI(+)-HRMS experiment indicated a molecular formula of $\mathrm{C}_{12} \mathrm{H}_{19} \mathrm{NO}_{6}$ with a $m / z$ of $274.1291[\mathrm{M}+\mathrm{H}]^{+}$(calcd. for $\mathrm{C}_{12} \mathrm{H}_{20} \mathrm{NO}_{6}{ }^{+}, 274.1285$, $\Delta \mathrm{ppm}=2.15$ ), which corresponded to 4 degrees of unsaturation. Analysis of the ${ }^{1} \mathrm{H}$ and ${ }^{13} \mathrm{C}$-DEPTQ NMR data of 4 showed the presence of two methyl groups at $\delta \mathrm{C} 15.6(\mathrm{C}-10)$ and $21.2(\mathrm{C}-12)$; 4 oximethines carbons at $\delta_{\mathrm{C}} 63.4(\mathrm{C}-4), 70.7$ (C-8), $74.4(\mathrm{C}-9)$, and $78.3(\mathrm{C}-5) ; 4$ olefinic carbons at $\delta_{\mathrm{C}} 122.8(\mathrm{C}-2), 127-7(\mathrm{C}-6)$, $135.4(\mathrm{C}-7)$, and 147.1 (C-3); two ester carbonyls at $\delta_{\mathrm{C}} 165.9$ (C1) and 172.6 (C-11). A n-nonane chain was easily followed through the COSY correlations from the ethylenic proton $\mathrm{H}-2$ to the methyl H-10. The HMBC correlation of the carbonyl C-1 with the olefinic set of protons $\mathrm{H}-2$ and $\mathrm{H}-3$ positioned the amide group at one side of the chain and an acetate group was placed on the other side thanks to the HMBC correlation of the carbonyl C11 to the oximethine $\mathrm{H}-9$ and to the methyl $\mathrm{H}-12$. The 9.8 and $11.3 \mathrm{~Hz}$ coupling constants for the sets of olefinic protons $\mathrm{H}-2 / \mathrm{H}-$ 3 and $\mathrm{H}-6 / \mathrm{H}-7$, respectively, demonstrated the cis configuration of both double bonds (Supplementary Figures 30-35). Moreover, 4 was identified as the new (4Z,8Z)-10-amino-3,6,7trihydroxy-10-oxodeca-4,8-dien-2-yl-acetate.

Compound 6 (F11) was isolated as an oil. The ESI(+)-HRMS experiment indicated a molecular formula of $\mathrm{C}_{10} \mathrm{H}_{14} \mathrm{O}_{4}$ with a $\mathrm{m} /$ $z$ of $199.0964[\mathrm{M}+\mathrm{H}]^{+}$(calcd. for $\mathrm{C}_{10} \mathrm{H}_{15} \mathrm{O}_{4}{ }^{+}, 199.0965, \Delta \mathrm{ppm}=$ 0.51 ), which corresponded to 4 degrees of unsaturation. Analysis of the ${ }^{1} \mathrm{H}$ and edited HSQC NMR data indicated the presence of two compounds, the minor one being $(3 R, 4 R)$ or $(3 S, 4 S)-4,5-$ dihydroxymellein. The major compound ( $1 \mathrm{~mol}$ for $0.5 \mathrm{~mol}$ of 4,5-dihydroxymellein) was linked to the following NMR signals: one methyl group at $\delta_{\mathrm{C}} 18.0(\mathrm{C}-10)$, six olefinic carbons at $\delta_{\mathrm{C}}$ 120.8 (C-2), 139.6 (C-3), 127.4 (C-4), 139.0 (C-5), 131.1 (C-8), and 129.5 (C-9), and two oximethines carbons at $\delta_{\mathrm{C}} 71.5(\mathrm{C}-6)$ and $76.9(\mathrm{C}-7)$. Sequential COSY correlation from the methyl $\mathrm{H}-$ 10 at $\delta_{\mathrm{H}} 1.67(\mathrm{dd}, J=6.5,1.5 \mathrm{~Hz})$ to $\mathrm{H}-9\left(\delta_{\mathrm{H}} 5.72\right), \mathrm{H}-8\left(\delta_{\mathrm{H}} 5.45\right)$, H-7 $\left(\delta_{\mathrm{H}} 3.92\right), \mathrm{H}-6\left(\delta_{\mathrm{H}} 4.45\right)$, and H-5 $\left(\delta_{\mathrm{H}} 5.72\right)$ defined one side of the molecule. HMBC correlations from $\mathrm{H}-7$ to C-5, C-6, and C9 and from the methyl $\mathrm{H}-10$ to $\mathrm{C}-9$ and $\mathrm{C}-8$ confirmed this assignment. The HMBC correlation of the carbonyl at $\delta_{\mathrm{C}} 170.0$ (C-1) with the olefinic proton $\mathrm{H}-3$ and the COSY correlation of $\mathrm{H}-3$ with an olefinic proton $\mathrm{H}-2$ at $\delta_{\mathrm{H}} 5.74$ positioned the carboxylic acid group in C-1. HMBC correlation of $\mathrm{H}-3$ with $\mathrm{C}-5$ and COSY correlation of $\mathrm{H}-3$ with the olefinic proton $\mathrm{H}-4$ at $\delta_{\mathrm{H}} 7.32$ and of $\mathrm{H}-4$ and $\mathrm{H}-5$ helped position the olefinic groups and link both chains. The $11.5 \mathrm{~Hz}$ coupling constant for the set of olefinic protons $\mathrm{H}-2 / \mathrm{H}-3$ and $\mathrm{H}-4 / \mathrm{H}-5$ demonstrated the cis configuration of those double bonds. The $15.2 \mathrm{~Hz}$ coupling constant for the third set of olefinic protons $\mathrm{H}-8 / \mathrm{H}-9$ demonstrated the trans configuration of the double bond (Supplementary Figures 42-47). Compound 6 was identified as the new $(2 Z, 4 Z, 8 E)$-6,7-dihydroxydeca-2,4,8-trienoic acid.

The NMR data of 15 and 16 were similar to the previously reported data for naphthoquinone spiroketals named CJ-12,372 (Sakemi et al., 1995) and palmarumycin EG1 (Macías-Rubalcava et al., 2014). However, their optical rotations were positive $(+2$ and +92 , respectively), while they were negative for CJ-12,372 and palmarumycin EG1 reported in an unidentified fungus and the endophyte Edenia gomezpompae, respectively. Compounds 15 and 16 were thus identified as the new naphthoquinone spiroketals enantiomers (+)-(R)-CJ-12,372 and (+)-(R)palmarumycin EG1 (Supplementary Figures 93-102).

Compound 17 (F32) was isolated as an oil. The ESI(-)-HRMS experiment indicated a molecular formula of $\mathrm{C}_{21} \mathrm{H}_{18} \mathrm{O}_{4}$ with a $\mathrm{m} / z$ of $335.1253[\mathrm{M}+\mathrm{H}]^{+}$(calcd. for $\mathrm{C}_{21} \mathrm{H}_{19} \mathrm{O}_{4}{ }^{+}, 335.1278, \Delta \mathrm{ppm}=$ 7.00) and a $\mathrm{m} / \mathrm{z}$ of $333.1253[\mathrm{M}-\mathrm{H}]^{-}$(calcd. for $\mathrm{C}_{21} \mathrm{H}_{17} \mathrm{O}_{4}{ }^{+}$, $333.1132, \Delta \mathrm{ppm}=0.51$ ), which corresponded to 13 degrees of unsaturation. ${ }^{1} \mathrm{H}$ and ${ }^{13} \mathrm{C}$ NMR spectra suggested that the molecule was a deoxypreussomerin derivative related to palmarumycin CP19 (Martínez-Luis et al., 2008). The signals for 1,8dihydronaphthalene ring system $\left(\delta_{\mathrm{H}} 6.92\right.$, dd, $J=7.4,0.9 \mathrm{~Hz}$, H-2'; 7.45, dd, $J=8.4,7.4 \mathrm{~Hz}, \mathrm{H}-3$ '; 7.51, dd, $J=8.4,0.9$ Hz, H-4'; 
7.50, dd, $J=8.4,0.8 \mathrm{~Hz}, \mathrm{H}-5$ '; 7.43, dd, $J=8.4,7.4 \mathrm{~Hz}, \mathrm{H}-6$ '; 6.85, dd, $\left.J=7.4,0.8 \mathrm{~Hz}, \mathrm{H}-7^{\prime}\right)$ and the substitution pattern in the nonaromatic ring $\left(\delta_{\mathrm{H}} 4.73, \mathrm{t}, J=3.2 \mathrm{~Hz}, \mathrm{H}-1,2.12, \mathrm{~m}, \mathrm{H}-2 \mathrm{a} ; 2.02, \mathrm{~m}, \mathrm{H}-\right.$ 2b; 2.20, m, H-3a; 2.14, m, H-3b) were identical in both molecules. However, the signals from the third aromatic ring were different, and the multiplicity $\left(\delta_{\mathrm{H}} 7.27, \mathrm{dd}, \mathrm{J}=6.8 \mathrm{~Hz}, \mathrm{H}-5 ; \delta_{\mathrm{H}} 6.93\right.$, dd, $\mathrm{J}=$ 6.8, $2.3 \mathrm{~Hz}, \mathrm{H}-6 ; \delta_{\mathrm{H}} 7.26$, dd, J = $2.3 \mathrm{~Hz}, \mathrm{H}-8$ ) indicated a $1,2,4-$ trisubstituted aromatic ring instead of a 1,2,3-trisubstituted aromatic ring in palmarumycin CP19. 17 has a single stereogenic center. Its absolute C-1 configuration was deduced by comparing the sign of the optical rotation with the one of the closely related palmarumycin CP19 (Martínez-Luis et al., 2008). Since the optical rotation of $(S)$-palmarumycin CP19 is negative and 17 has a positive optical rotation, the C-1 configuration was thus determined as $R$ (Supplementary Figures 103-106). Compound 17 was identified as the new molecule (R)-4methoxy-3,4-dihydro-2H-spiro[naphthalene-1,2'-naphtho[1,8-de] [1,3]dioxin]-6-ol.

Naphthoquinone spiroketals as palmarumycins belong to a class of natural products isolated from various fungal cultures, exhibiting a wide range of biological properties (Cai et al., 2010). Compounds such as palmarumycin LP1 and cladospirone have been isolated from Lasiodiplodia pseudotheobromae (Lü et al., 2014).

\section{Deep Metabolome Analysis of the Lasiodiplodia venezuelensis Strain and Search for Analogs of the Bioactive 5-Hydroxymellein 18}

In order to obtain a comprehensive survey of the metabolome of L. venezuelensis, the 33 fractions obtained after semi-preparative separation were profiled using data-dependent UHPLC-HRMS/ MS. These data were combined with the metabolite profiling of the A02EtM enriched extract used for dereplication. The extract and the fractions MS/MS data were gathered and organized into a single molecular network ( $\mathrm{MN}$ ) (Figure 3). The resulting $\mathrm{MN}$ for positive ion data allowed the grouping of 8,500 spectra in 840 clusters. Interestingly, the constitution of this global $\mathrm{MN}$ allowed highlighting approximately three times more features than for the extract metabolite profile alone. All the steps and tools involved in the creation of the $\mathrm{MN}$ are detailed in the experimental section.

Annotation was performed against an in-house database containing the in silico fragmentation spectra of all the compounds present in the DNP (DNP-ISDB) (Allard et al., 2016). Spectral matching against this DB provided a list of the top 50 chemical structures for each node (initial rank). A taxonomic reweighting step allowed the candidate structures to be re-ranked with a weight inversely proportional to the distance between the biological source of the candidate and that of the analyzed sample (species: Lasiodiplodia venezuelensis, genus: Lasiodiplodia, family: Botryosphaeriaceae) (Rutz et al., 2019). The top six candidates were finally retained (final rank). The annotation was also checked at the MS1 level by verifying the molecular formula of all features after heuristic filtering (Kind and Fiehn, 2007). For all clusters, a consensus structural annotation was returned at the different Classyfire taxa levels (superclass, class, subclass, and parent) (Djoumbou Feunang et al., 2016). The annotation table reports only the top-ranked structures that gave a taxonomically relevant output and/or for which there was a structural consistency in the annotation of the corresponding clusters (Supplementary Tables 1-2). The full MS data set was uploaded and is accessible on the GNPS servers as Massive Data set $n^{\circ}$ MSV000086605.

Pie charts on the nodes and their proportions refer to the relative intensities of the ions in the extract (dark coral pink) or in the fractions (light coral pink), based on the respective areas of the corresponding extracted ion chromatography (XIC). The numbering of the clusters corresponds to the component index number.

In order to have a confident annotation of the largest possible number of metabolites, all nodes corresponding to the protonated molecule of the 18 isolated compounds were located in the MN (Figure 3) and occurred in nine clusters.

In a first instance, the $\mathrm{MN}$ was analyzed to assess the presence of potential analogs of the active compound 18. For this, two clusters containing the nodes of all isolated mellein derivatives were analyzed in-depth to evidence additional putative isocoumarin analogs: cluster C_54 (7 (F13), 13 (F22), 18 (F19)) and C_13 (8 (F14), 9 (F16)), (Figure 3 and Figures $6 \mathrm{~B}, \mathrm{C})$. All these nodes were thus unambiguously identified.

For cluster C_54, the occurrence of three isocoumarins demonstrated a good consistency of the annotation and allowed assigning its consensus chemical family to benzopyrans. The MS/MS and molecular formula of all the related features and their taxonomical occurrence (class Dothideomycetes, family Bothryosphaeriaceae, order Bothryosphaeriales, genus Lasiosiplodia) were carefully analyzed. This enabled annotating with good confidence eight additional nodes ( $\mathrm{n} 2$ and $\mathrm{n} 8$ ) as isocoumarin derivatives (Figure 6B). This seems consistent since mellein, dihydroxymellein, methylisocoumarins, and isocoumarins have a common biosynthetic pathway related to fatty acid biosynthesis catalyzed by polyketides synthases (PKS) (Reveglia et al., 2020).

The other two isolated mellein derivatives 8 and 9, bearing a hydroxyl in position 4, were located in C_13 (Figure 6C). In this smaller cluster, several additional nodes were found to be related to 5 , another structurally different benzopyran. The node $n 10$ could be putatively annotated as another mellein derivative found in the Bothryosphaeriaceae family (Xu et al., 2012) (Figure 6C).

Overall, the dereplication of this cluster using the isolated molecules as anchor points showed that the extract potentially contained analogs of the active compound 18. All these annotated compounds were located in the fractions in which they mainly occur. Based on the semi-preparative fractionation and continuous bioactivity monitoring (Figure 1), a hypothetical assessment of their possible anti-Wnt or cytotoxic effects was performed. Figure 6A shows the location of each feature in the fractions, alongside the activity of the fraction. This is represented as a histogram ordered according to the fractionation process illustrated in Figure 1. Among all 19 isolated and annotated structural analogs of 18 , this approach shows that the large majority have neither Wnt inhibition (no reduction of Wnt 

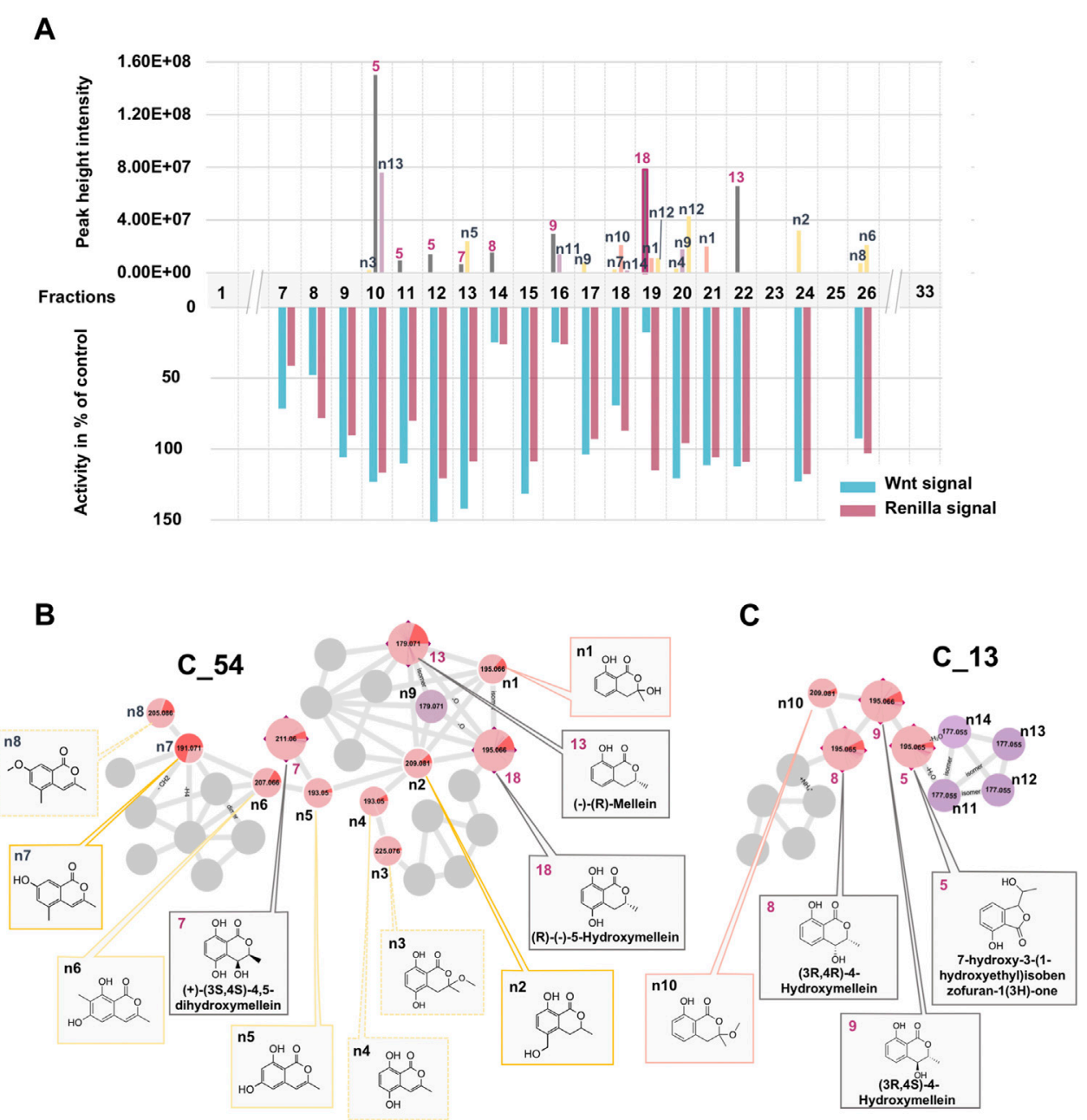

Isolated molecule

Annotated feature- Found in the Family Botryosphaeriaceae

Annotated feature- Found in the class Dothideomycetes

Annotated feature- Found in the phylum Ascomycota

Manually annotated feature- Propagation

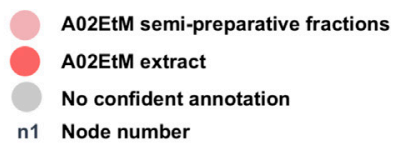

n1 Node number

FIGURE 6 | Detailed view of the fraction composition and bioactivity across all fractions containing isocoumarins analogs. (A) Histogram represented as a function of the 33 collected fractions showing the peak height intensity of the related putative analogs and their occurrence in the fractions. Associated is the activity of each fraction: in blue, activity on Wnt signal (inhibition activity), in pink, effect on Renilla signal (cytotoxicity). Fraction F19 is considered as specifically active since it inhibits Wnt signaling without having an impact on Renilla signaling. (B) Cluster C_54 containing node 18 corresponding to compound 18, isolated (7, 13) and hypothetical (n1-8) analogs. (C) Cluster C_13 containing isolated $(5,8,9)$ and hypothetical $(n 10-14)$ analogs.

signal) nor cytotoxicity (no reduction of Renilla signal) (Figure 6).

Interestingly, two fractions F14 and F16 showed important Wnt inhibition but also similar cytotoxic effects. They were found to contain 8 (F14), 9 (F16), and $\mathrm{n} 11$ (F16). All these compounds are 4-hydroxy derivatives without hydroxyl in position 5, while 18 did not have any hydroxylation in 4 . However, the $\mathrm{IC}_{50}$ determination of the pure 8 and 9 demonstrated that they did not show any cytotoxicity up to high concentrations (see Figures 2B,C). The annotated compound n11 could not be isolated but might contribute to the cytotoxicity of fraction F16. Fraction 18 showed a moderate Wnt effect and equivalent cytotoxicity. This could be related to the presence of the annotated compound $\mathrm{n} 10$, which has possibly no hydroxylation in position 4 , as this was the case for 18. Overall, the analyses of all fractions and their content and the activity measurement showed an important selectivity of 18 for Wnt inhibition, whereas the majority of derivatives had no effect.

The $\mathrm{IC}_{50}$ measurement of isolated compounds $(7,8,9,13)$ confirmed that these compounds did not show any specific inhibition of Wnt3a-induced signal up until estimated concentrations of $\sim 500 \mu \mathrm{M}$, indicating that 18 acts in a highly 


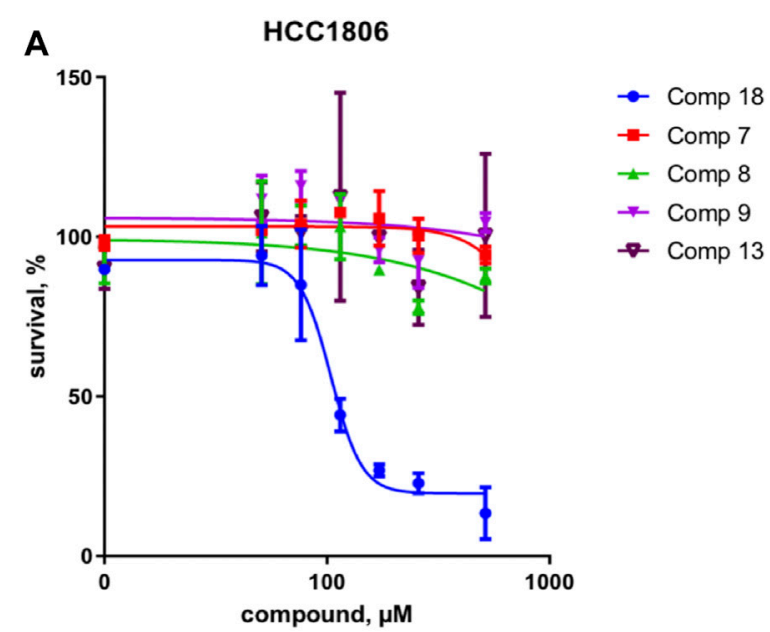

B

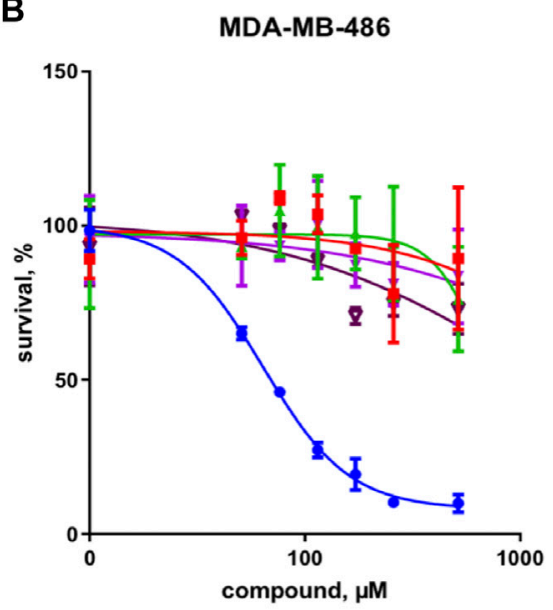

C

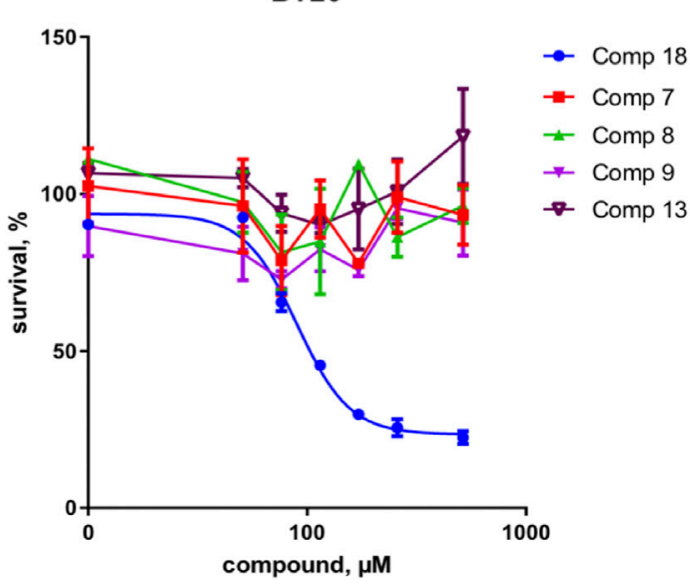

FIGURE 7 | Survival of three different TNBC cancer cell lines in \% of control for compounds 18 and 7, 8, 9, and 13 in (A) HCC 1806, (B) MDA-MB486 , and (C) BT20 cell lines. Compound 18 inhibits the proliferation of three TNBC cell lines and thus shows a broad effect on the TNBC cell types. specific manner (Figure 2B). Moreover, we have confirmed that 18 is very specific to Wnt inhibition and shows some acute unspecific toxicity only at very high concentrations (cytotoxic $\mathrm{IC}_{50}$ estimate is at $\sim 800 \mu \mathrm{M}$, (Figure $2 \mathrm{C}$ ). Finally, by assessing the activity of 18 when the Wnt pathway was stimulated downstream through GSK3beta inhibition, we demonstrated that it is highly selective for upstream components of the pathway since inhibition of CHIR99021 signal occurs only at cytotoxic concentrations and is thus unspecific (Figure 2D).

These results were complemented by analyzing if this activity against the upstream component of the Wnt pathway can be translated into the inhibition of the cancer cell growth. Indeed, only the mellein 18 was able to inhibit the proliferation of three TNBC cell lines (Figures $7 \mathrm{~A}-\mathrm{C}$ ). Interestingly, the $\mathrm{IC}_{50}$ of this effect was rather different across the cell lines, indicating that their sensitivity is likely regulated by the expression levels of the potential target. The small set investigated indicated the specificity of 18 among the series of analogs within the strain. A larger set of other mellein derivatives would be interesting to investigate. The use of MS-targeted isolation performed at a larger scale could be considered in the future for the selective isolation of some of the minor analogs detected.

\section{Annotation of the Metabolome of the Lasiodiplodia venezuelensis Strain Based on all Isolated Compounds}

We took advantage of having isolated in one step several main metabolites of the L. venezuelensis extract including the new compounds to evaluate the presence of their analogs, following the same strategy as for the active compound 18 . This provided an overview of its metabolome composition.

Compounds 1-4, 6, 10-12, 14, and 15-17 were found to be spread across seven additional clusters (Figure 3) to those containing isocoumarin derivatives (C_54 and C_13).

The new pyran derivative 1 was attributed to node $C_{-} 28 \_1$. Two additional analogs, putatively annotated as diplopyrone in the Botryosphaeriaceae family, and another pyranone were evidenced (nodes C_28_n1 and n2, Supplementary Figures 107). Similarly, the new pyranone derivative 3 was attributed to $\mathrm{C}_{-} 23$-3 and compound 4 was also present in the cluster (C_23_4). We have assumed that those two molecules are in the same cluster because 3 could correspond to a cyclized form of 4 (Supplementary Figures 108). C_23_n1 and n2 bearing a pyranone core structure similar to 3 were also annotated in this cluster. As said previously, apart from isocoumarins, such $2 \mathrm{H}$-pyran-2-one derivatives have been isolated from $L$. theobromae (lasiolactone and massoialactone) (Matsumoto and Nago, 1994). Another pyran-2-one derivative has been isolated from a strain of Lasiodiplodia PSU-M114 as tetrahydro-4hydroxy-6-propylpyran-2-one (Rukachaisirikul et al., 2009).

Compounds 2, 6, and 14 were spotted in three different clusters of fatty acyl derivatives (C_1,497, C_43, and C_164, Supplementary Figures 109). They are new to this family of fungi, but diverse free fatty acids and their esters have been identified in the cultures of botryosphaeriaceous fungi 
(Uranga et al., 2016). Free fatty acids are important as they are the starting material of many secondary metabolites such as oxylipins, and a source of acetyl CoA required for polyketides produced by Botryosphaeriacae. They are also involved in plant growth regulation, virulence, and plant-fungi communication (Salvatore et al., 2020).

The butyrolactones 10 and 11 occurred in cluster C_97 (nodes C_97_10 and C_97_11, Supplementary Figures 110). They have previously been isolated for L. theobromae and are often found in this genus. In the same cluster, $\mathrm{n} 1$ and $\mathrm{n} 2$ were manually annotated based on their fragmentation pattern. Nodes $n 3$ and $\mathrm{n} 4$ correspond to butyrolactone derivatives with higher molecular weight. n3 is a metabolite reported in the Botryospheariales. Another analog, decumbic acid B (12), was isolated, but its associated feature could not be evidenced in the $\mathrm{MN}$ in positive mode since it ionizes in negative mode only (Supplementary Figures 111). It is the first report of its occurrence in the genus.

The naphthoquinone spiroketals 15 and 16 were associated with nodes C_72_15 and C_72_16 (Supplementary Figures 112). Two nodes $n 1$ and $n 2$ corresponding to naphthoquinone spiroketals were annotated as palmarumycins isolated from fungi from the Dothideomycetes class (Xu et al., 2015). The nodes $\mathrm{n}$ and $n 6$ were attributed to potential isomers of 16 and $n 3$. The other derivative 17 did not belong to this cluster and occurred as a single node which can be explained by a different fragmentation pattern related to the position of the hydroxy group. The presence of three new naphthoquinone spiroketals (15,16, and 17) and several derivatives detected by $\mathrm{MN}$ shows the biosynthetic potential this strain. This kind of compounds was never reported in the genus Lasiodiplodia.

Following this strategy, nine clusters were assigned to five chemical classes and significantly increase metabolome information on this strain. All annotations performed were carefully checked with respect to taxonomic consistency and/ or annotation propagation from the compounds unambiguously identified by NMR following our one-step isolation strategy. This provided good confidence for the identification of the various analogs highlighted.

Several metabolites found in the remaining clusters were annotated solely on the basis of the comparison of their MS/ MS pattern against the in silico fragmentation database and the taxonomical re-ranking. This made it possible to highlight the presence of ubiquitous fungal chemical families such as various steroids, lipids, and amino acid derivatives. Metabolites more specifically occurring in the Botryosphaeriaceae were also highlighted and include jasmonates (cyclic ketone) derivatives (Tsukada et al., 2010; Andolfi et al., 2014), benzopyrans (Rukachaisirikul et al., 2009; Salvatore et al., 2020), and lactones derivatives such as as lasiodiplodins (Shen et al., 2015), dioxanes (Rukachaisirikul et al., 2009), and depsidones (Umeokoli et al., 2019). The annotation of the corresponding features is available in Supplementary Table 2 and Supplementary Figures 113-120.

The annotation of the metabolome of this strain shows that the most represented chemical families correspond to those reported for the genus Lasiodiplodia, which shows good consistency and has revealed the presence of many analogs not yet described in this genus.

The inclusion of metabolite enriched fractions to the MN metabolite profiling enables the detection of many additional minor constituents of the metabolome, further revealing the biosynthetic potential of this strain. This deep metabolome characterization is worth further investigating but would require working at a much larger scale with the current technologies for both biological assessment and precise structural assignment of the wealth of metabolites present.

\section{CONCLUSION}

Inhibition of Wnt signaling is a highly desired mode of action for targeted agents against TNBC and a number of other cancers due to its efficacy, especially against the tumor recurrence (Zhan et al., 2017; Steinhart and Angers, 2018). However, all attempts to inhibit this pathway did not result in clinically approved agents due to the safety concerns on clinical and/or preclinical stages. Largely, this is the result of direct, unselective inhibition of the pathway, leading to disruption of its functioning in healthy tissues (Shaw et al., 2019a). Nevertheless, the pathway structure allows finding cancer-selective compounds; as such, they must target the upstream components (Shaw et al., 2019b). We have identified novel Wnt inhibitory properties of the mellein derivative 18 and validated it as an inhibitor of upstream levels of the pathway. Inhibition seems to be highly specific to the arrangement of this exact scaffold since a variety of similar compounds do not show inhibitory activity. As expected for a Wnt inhibitor, the compound is able to efficiently inhibit the proliferation of three TNBC cell lines. Of note, the growth inhibition is observed within the same range as the Wnt signal decrease, thus further emphasizing the specificity of the compound's action. Overall, our results lay a solid foundation for further development of 18 and, likely, its potency can be enhanced by further modifications, especially if driven by further identification of its molecular target. The approach used in this study allowed the direct isolation and study of analogs of 18 and shows the presence of several additional minor derivatives in the strain. Interestingly, it has been shown that a mellein derivative, O-methylmellein, was strongly induced when Botryosphaeria obtusa (Botryosphaeriaceae) was in confrontation with another wood-decaying fungus Eutypa lata and exhibited toxicity towards other fungi (Glauser et al., 2009). Confrontation experiments with $L$. venezuelensis might be an interesting way to obtain new bioactive analogs of 18 . In that respect, it would be interesting to test 18 against other targets as fungi or bacteria.

Overall, the high throughput semi-preparative HPLC-UV fractionation using dry load injection, combined with UHPLCPDA microfractionation, led to the isolation of 18 compounds from Lasiodiplodia venezuelensis. Five are original natural compounds de novo identified in this study. Seven are new to the Botryosphaeriaceae family, or analogs of compounds related to this family of fungi. In addition to the discovery of a Wnt inhibitor of interest, the UHPLC-HRMS/MS metabolite profiling and the MN contribute to characterize better the metabolome of 
L. venezuelensis and its large biosynthetic potential. The metabolome information on this strain and other strains of the community may provide an interesting complement to metagenomic approaches applied to Astrocaryum and its ecosystem (Donald et al., 2020).

This work also stresses the importance of carefully assessing purity through appropriate methods for an accurate bioactivity assessment. Indeed, as illustrated here, the activity can be due to minor compounds and raises the question of residual complexity when compounds are isolated from natural product extracts (Choules et al., 2018). Nevertheless, as shown in the present study, the comprehensive workflow developed that combines UHPLC-HRMS/MS dereplication, targeted microfractionation, NMR, and qNMR helped to successfully assign the bioactivity to the right constituent and assess the link between the analogs present and bioactivity in a complex fungal strain extract.

\section{EXPERIMENTAL SECTION}

\section{General Experimental Procedures}

NMR spectroscopic data were recorded on a Bruker Avance Neo $600 \mathrm{MHz}$ NMR spectrometer equipped with a QCI $5 \mathrm{~mm}$ Cryoprobe and a SampleJet automated sample changer (Bruker BioSpin, Rheinstetten, Germany). Chemical shifts are reported in parts per million $(\delta)$ using the residual $\mathrm{CD}_{3} \mathrm{OD}\left(\delta_{\mathrm{H}} 3.31 ; \delta_{\mathrm{C}} 49.0\right)$ or DMSO- $d_{6}\left(\delta_{\mathrm{H}} 2.50 ; \delta_{\mathrm{C}} 39.5\right)$ as internal standards for ${ }^{1} \mathrm{H}$ and ${ }^{13} \mathrm{C}$ NMR, respectively, and coupling constants $(J)$ are reported in $\mathrm{Hz}$. Complete assignments were obtained based on 2D-NMR experiments: COSY, ROESY, edited HSQC, and HMBC. HRESIMS data were obtained on a Q-Exactive Focus mass spectrometer (Thermo Scientific, Bremen, Germany), using heated electrospray ionization (HESI-II) source. Analytical HPLC was carried out on a HP 1260 system equipped with a photodiode array and an ELSD detector (Sedere, Alfortville, France). Semi-preparative HPLC-UV analyses were conducted on a Shimadzu system (Kyoto, Japan) equipped with LC-20A module pumps, a SPD-20A UV/VIS, a 7725I Rheodyne ${ }^{\circledR}$ valve, and a FRC-10A fraction collector. The system is controlled by the software LabSolutions from Shimadzu.

\section{Electronic Circular Dichroism and Optical Rotation}

The spectra obtained by electronic circular dichroism (ECD) and UV were analyzed on a J-815 circular dichroism spectrometer (Loveland, CO, United States). The solvent used was methanol. The cell temperature was $24.5^{\circ} \mathrm{C}$ and stabilized using a thermostat ED circulation bath (Julabo, Seelbach, Germany) and a PFD-350S thermostat (Jasco). The set scan speed was $200 \mathrm{~nm} / \mathrm{min}$ in continuous mode with a scan start at $800 \mathrm{~nm}$ and an end at $200 \mathrm{~nm}$. The optical rotations were measured in methanol solutions on Jasco P-1030 polarimeter in a $1 \mathrm{~cm}$ tube.

\section{Plant Material}

Astrocaryum sciophilum palm tree leaves were sampled in August 2017 at the Nouragues ecological research station in
French Guiana. Leaf samples were collected at the Inselberg research station $\left(4^{\circ} 05^{\prime} \mathrm{N}-52^{\circ} 41^{\prime} \mathrm{W}\right)$ by randomly cutting $5 \times$ $3 \mathrm{~cm}$ pieces of fresh leaflets and rachis from individual plants using sterile tweezers. The pieces were placed in Eppendorf tubes containing Potato Dextrose Broth 1/4 (PDB) medium to allow regrowth of the fungi and tubes containing cetyltrimethylammonium bromide (CTAB) to preserve the genetic material. Petri dishes containing "potato dextrose agar" medium and aureomycin were also left open on the stipe in order to sample fungi from the environment close to the palm tree. These media were enriched with aureomycin to avoid the growth of bacteria and promote the growth of fungi only.

\section{Isolation of Endophytes}

The surface of the plant fragments was thoroughly washed for 3 hours under a stream of tap water in a suitable container and then washed in three successive baths of sterile water for $10 \mathrm{~min}$ each under a laminar flow hood. This non-chemical surface cleaning method was used to reduce the possible loss of diversity due to aggressive sterilization using alcoholic solutions or even Paraquat (Gindrat and Pezet, 1994). The surface-sterilized leaves were aseptically cut into small segments $\left(0.5 \mathrm{~cm}^{2}\right)$, placed individually in Petri dishes containing potato dextrose agar medium (PDA, Potatoe Dextrose Agar, Sigma-Aldrich, Germany), amended with aureomycin $\left(25 \mathrm{ppm} . \mathrm{L}^{-1}\right)$ in $9 \mathrm{~cm}$ Petri dishes, and cultured at room temperature. Each individual emerging hypha fragment was removed and placed in $9 \mathrm{~cm}$ Petri dishes containing PDA and aureomycin. The isolated and selected strains were then individually cultured on a small scale in $9 \mathrm{~cm}$ Petri dishes containing PDA medium without aureomycin. Each strain has been integrated into the dynamic fungal library of Agroscope, whose content is available on the web (database Mycoscope: www.mycoscope.ch), in vials containing $5 \mathrm{ml}$ of diluted PDB (PDB, Potato Dextrose Broth, Sigma-Aldrich, Germany) aqueous solution $(1: 4)$ at $4^{\circ} \mathrm{C}$.

\section{Identification of Fungal Strains}

Identification of the isolated strains was performed by extraction of the ribosomal DNA (phenol/chloroform), PCR amplification of the ITS1F and ITS4 region, and sequencing (Fasteris, Geneva, Switzerland). The obtained sequences were then submitted to BLAST on NCBI (https://blast.ncbi.nlm.nih.gov/Blast.cgi) to identify the strain. The specimens were then entered in the dynamic mycotheca of Agroscope and registered in the fungal database (www.mycoscope.ch) under the reference numbers 1883 to 2024 .

\section{Culture and Extraction}

Each strain was cultivated at $21^{\circ} \mathrm{C}$ under alternating light and dark (12 h each) in $10 \mathrm{~cm}$ Petri dishes containing PDA culture medium. The culture medium was then extracted by maceration in ethyl acetate (EtOAc) for $24 \mathrm{~h}$ at room temperature under agitation. The organic phase was recovered by vacuum filtration and washed three times with Millipore Corporation (MilliQ) water. The organic and water phases were dried under reduced 
pressure with a rotary evaporator to yield crude mixtures. Agar from uninoculated PDA plates was used as controls.

\section{Scale-Up of the Fungal Culture of Lasiodiplodia venezuelensis}

Strains were cultivated for 15 days at room temperature in $14 \mathrm{~cm}$ Petri dishes containing PDA medium. Culture media were then consecutively extracted three times by maceration in EtOAc for $24 \mathrm{~h}$ at room temperature under agitation (after each $24 \mathrm{~h}$ maceration, the organic phase was harvested and the medium was macerated again in renewed EtOAc). The combined organic solution was washed three times with MilliQ water. The organic and water phases were dried under reduced pressure with a rotary evaporator to yield the ethyl acetate fraction (Et) and the water fraction (W). The Et fraction was then degreased by liquid/liquid partition in a hexane/methanol:water (1/1) system with methanol:water (7: $3)$ to give the hexane $(\mathrm{EtH})$ and the methanol/water fraction (EtM) (Supplementary Figure 1). Large-scale cultivation of the Lasiodiplodia venezuelensis strain was conducted on $10014 \mathrm{~cm}$ Petri dishes to yield the factions A02Et $(1 \mathrm{~g})$ and A02W (335 mg). $600 \mathrm{mg}$ of the fraction A02Et was then degreased to yield fractions A02EtH $(320 \mathrm{mg})$ and A02EtM (250 mg).

\section{UHPLC-PDA-CAD-HRMS/MS Analysis}

Metabolite profiling of the extracts was performed by UHPLCPDA-CAD-HRMS/MS as follows. The separation was achieved on an Acquity BEH C18 column $(2.1 \times 50 \mathrm{~mm} ; 1.7 \mu \mathrm{m})$. The temperatures in the autosampler and in the column oven were, respectively, set at 10 and $40^{\circ} \mathrm{C}$. The mobile phase constituted of water (A) and acetonitrile (B), both containing $0.1 \%$ formic acid; the separation was performed with a linear gradient from 5 to $100 \%$ of B in 7 min followed by a $1 \mathrm{~min}$ isocratic step at $100 \%$ of B. The flow rate was set at $600 \mu \mathrm{L} / \mathrm{min}$ and the injection volume was set at $2 \mu \mathrm{L}$. The optimized HESI-II parameters were as follows: source voltage, $3.5 \mathrm{kV}$ (pos), $4 \mathrm{kV}$ (neg); sheath gas flow rate $\left(\mathrm{N}_{2}\right), 55$ units; auxiliary gas flow rate, 15 units; spare gas flow rate, 3.0 ; capillary temperature, $275^{\circ} \mathrm{C}$ (pos), $320^{\circ} \mathrm{C}$ (neg); S-Lens RF Level, 45. The data-dependent MS/MS events were performed on the four most intense ions detected in full-scan MS (top three experiments). The MS/MS isolation window width was $1 \mathrm{Da}$, and the normalized collision energy was set to 35 units. In data-dependent MS/MS experiments, full scans were acquired at a resolution of 35,000 FWHM (at $200 \mathrm{~m} / z$ ) and MS/MS scans at $17,500 \mathrm{FWHM}$, both with a maximum injection time of $50 \mathrm{~ms}$. After being acquired in a MS/MS scan, parent ions were placed in a dynamic exclusion list for 2.0. In positive mode, the di-isoctyl phthalate $\mathrm{C}_{24} \mathrm{H}_{38} \mathrm{O}_{4}[\mathrm{M}+\mathrm{H}]^{+}$ion $(\mathrm{m} / z$ 391.28429) was used as an internal lock mass. The mass analyzer was calibrated using a mixture of caffeine, methionine-arginine-alanine-acetate (MRFA), sodium dodecyl sulfate, sodium taurocholate, and Ultramark 1,621 in an acetonitrile/methanol/water solution containing $1 \%$ formic acid by direct injection. An Acquity UPLC photodiode array detector was used to acquire UV spectra detected in the $200-500 \mathrm{~nm}$ range.

\section{UHPLC-HRMS/MS Data Processing}

The raw files containing UHPLC-HRMS/MS data were converted into mzXML files using the msConvert software. The mzXML files were then processed using MZmine (v2.51) (Pluskal et al., 2010). Mass detection was carried out using a centroid mass detector with a noise level set at $5 \mathrm{E}^{4}$. The ADAP chromatogram builder was employed with a minimum height of $5 \mathrm{E}^{4}$, a minimum group size of scans of 5 , a minimum group intensity threshold of $5 \mathrm{E}^{4}$, a minimum highest intensity of $5 \mathrm{E}^{4}$, and a $m / z$ tolerance of $8 \mathrm{ppm}$. The wavelets ADAP algorithm was used for chromatogram deconvolution with the following settings: a single-to-noise $(\mathrm{S} / \mathrm{N})$ threshold of 10 , intensity window $\mathrm{SN}$, a minimum feature height of $5 \mathrm{E}^{4}$, a coefficient area threshold of 100 , a peak duration range between 0.02 and $0.9 \mathrm{~min}$, and a wavelet range between 0.00 and $0.05 \mathrm{~min}$. The $\mathrm{m} / z$ and retention time (RT) ranges for $\mathrm{MS}^{2}$ scan pairing were, respectively, set to $0.025 \mathrm{Da}$ and $0.1 \mathrm{~min}$. The chromatograms were deisotoped using the isotope peak grouper algorithm with a $\mathrm{m} / \mathrm{z}$ tolerance of $8 \mathrm{ppm}$, a RT tolerance of $0.08 \mathrm{~min}$, and a maximum charge of 2 , while the representative isotope used was the most intense. The peak alignment was performed using the join aligner method with a $\mathrm{m} / \mathrm{z}$ tolerance of $8 \mathrm{ppm}$, a RT absolute tolerance of $0.05 \mathrm{~min}$, and a weight for $\mathrm{m} /$ $z$ and RT at 20. An adduct search $\left(\mathrm{Na}^{+}, \mathrm{K}^{+}, \mathrm{NH}_{4}{ }^{+}, \mathrm{ACN}^{+}\right.$, and $\mathrm{HCOOH}$ ) was performed on the peak list with an RT tolerance of $0.01 \mathrm{~min}$, a $\mathrm{m} / \mathrm{z}$ tolerance of $8 \mathrm{ppm}$, and a maximum relative peak height of $1,000 \%$. A complex search was performed on the peak list with an RT tolerance of $0.01 \mathrm{~min}$, a $\mathrm{m} / z$ tolerance of $8 \mathrm{ppm}$, and a maximum relative peak height of $1,000 \%$. The peak list was then gap-filled using the same RT and $m / z$ range gap filler with a $\mathrm{m} / \mathrm{z}$ tolerance of $8 \mathrm{ppm}$. A custom database of the fungi group (17,255 compounds) was applied for in silico identification from the Dictionary of Natural Product (DVD version 26.2) (Dictionary of Natural Pro, 2020).

\section{Molecular Network Analysis}

The MZmine files were exported in MGF format for the processing of the molecular network (MN) in the Global Natural Products Social (GNPS) platform (Wang et al., 2016). In order to maintain the RT and exact mass information and allow isomer separation, feature-based $\mathrm{MN}$ was created using the MGF file resulting from the MZmine pre-treatment steps detailed above. The spectral data were then uploaded on the GNPS MN platform. A network was created where edges were filtered to have a cosine score above 0.65 and more than six matched peaks. Further edges between two nodes were kept in the network if and only if each of the nodes appeared in each other's respective top 10 most similar nodes. The spectra in the network were then searched against GNPS' spectral libraries. All matches kept between network spectra and library spectra were required to have a score above 0.7 and at least six matched peaks. The analogs spectra were searched against the DNP-ISDB database (Allard et al., 2016). The top $502 \mathrm{D}$ chemical structures were provided for each node according to the in silico MS/MS fragmentation spectra match, called "initial rank." A chemotaxonomical filter was applied to weight the search according to the occurrence of structures in Botryosphaeriaceae to give a ranking of the top 
six most probable structures and was called "final rank." The output was visualized using Cytoscape v3.7.1 (https://cytoscape. org/). Peak areas of different analyses were represented as pie chart diagrams. Node sizes were proportional to the peak areas of the extract. The full MS dataset is uploaded and accessible on the GNPS servers as Massive Data set $n^{\circ}$ MSV000086605.

\section{HPLC-PDA-ELSD Analyses}

HPLC-PDA analyses were conducted as follows: Waters ${ }^{\circledR}$ X-bridge C18 column $(250 \times 4.6 \mathrm{~mm}$ i. d., $5 \mu \mathrm{m})$ (Waters ${ }^{\circledR}$, Milford, MA, United States) equipped with a Waters ${ }^{\circledR}$ C18 pre-column cartridge holder $(20 \times 4.6 \mathrm{~mm}$ i.d. $)$; solvent system $\mathrm{H}_{2} \mathrm{O}(\mathrm{A})$ and $\mathrm{MeOH}(\mathrm{B})$, both containing $0.1 \%$ formic acid (FA). The column was equilibrated with $5 \%$ of $B$ for $15 \mathrm{~min}$. The separation was performed with a gradient mode from 5 to $60 \%$ of B over $70 \mathrm{~min}$, then from 60 to $100 \%$ of B over $20 \mathrm{~min}$. The column was then washed with $100 \%$ of $\mathrm{B}$ for $10 \mathrm{~min}$ and equilibrated with $5 \%$ of $\mathrm{B}$ over $15 \mathrm{~min}$. The flow rate was $1 \mathrm{ml} /$ min, the injection volume $20 \mu \mathrm{L}$, and the sample concentration $1 \mathrm{mg} / \mathrm{ml}$ in $\mathrm{MeOH}$. The UV absorbance was measured at 254 and $280 \mathrm{~nm}$ and the ELSD set at $45^{\circ} \mathrm{C}, 3.5$ bar $\mathrm{N}_{2}$, gain 8 .

\section{UHPLC-UV-ELSD-QDa Analyses}

UHPLC-UV-ELSD-QDa analyses were performed on an Acquity BEH C18 column $(2.1 \times 50 \mathrm{~mm} ; 1.7 \mu \mathrm{m})$ using a mobile phase consisting of water (A) and acetonitrile (B), both with $0.1 \%$ FA. The separation was performed with a linear gradient from 5 to $100 \%$ of B in $7 \mathrm{~min}$ followed by a $1 \mathrm{~min}$ isocratic step at $100 \%$ of $\mathrm{B}$. The flow rate was set at $600 \mu \mathrm{L} / \mathrm{min}$ and the injection volume at $2 \mu \mathrm{L}$. The temperatures in the autosampler and in the column oven were, respectively, set at 10 and $40^{\circ} \mathrm{C}$. UV data were acquired from 200 to $600 \mathrm{~nm}$ and the ELSD temperature was set at $45^{\circ}$, the pressure at 3.5 bars,, and the gain at 8 . Mass data were obtained by a fully automated acquisition at $10 \mathrm{~Hz}$ for $\mathrm{m} / z$ between 100 and 1,000. Data acquisition, instrument control, and data processing were performed with the Masslynx ${ }^{\circledR}$ software (Waters ${ }^{\circledR}$ ).

\section{Semi-Preparative HPLC-UV Purification of the Hydro Alcoholic Fraction of the Strain Lasiodiplodia venezuelensis (A02EtM)}

Semi-preparative HPLC-UV analyses were conducted as follows: Waters ${ }^{\circledR}$ X-bridge C18 column $(250 \times 19 \mathrm{~mm}$ i.d., $5 \mu \mathrm{m}$ ) equipped with a Waters ${ }^{\circledR} \mathrm{C} 18$ pre-column cartridge holder $\left(10 \times 4.6 \mathrm{~mm}\right.$ i.d); solvent system $\mathrm{H}_{2} \mathrm{O}$ (A) and $\mathrm{MeOH}$ (B), both containing $0.1 \%$ FA. The column was equilibrated with $5 \%$ of $\mathrm{B}$ for $15 \mathrm{~min}$. The separation was performed with a gradient mode from 5 to $60 \%$ of $\mathrm{B}$ over $71.63 \mathrm{~min}$, then from 60 to $100 \%$ of $\mathrm{B}$ over $21.46 \mathrm{~min}$. The column was then washed with $100 \%$ of B for $10 \mathrm{~min}$ and equilibrated with $5 \%$ of $\mathrm{B}$ over $15 \mathrm{~min}$. The flow rate was $17 \mathrm{ml} / \mathrm{min}$. These conditions were calculated from a geometric gradient transfer from the analytical HPLC using the software developed by Guillarme et al. (Guillarme et al., 2008). The UV traces were recorded at 254 and $280 \mathrm{~nm}$. The HPLC-UV chromatograms of the different separation are shown (Supplementary Figure 2). The A02EtM extract (10,
$30,35,32$, and $32 \mathrm{mg}$ ) was injected in the semi-preparative HPLC-UV using dry load. The dry load injection was performed using a dry load cell, i.e., a commercial small aluminum precolumn cartridge from Waters ${ }^{\circledR}(10 \times 19 \mathrm{~mm}$ i.d. $)$ that was opened on one side. The extract was mixed with the same ratio of stationary phase $\left(\mathrm{C} 18\right.$ Zeoprep $\left.{ }^{\circledR} 40-63 \mu \mathrm{m}\right)$, and this mixture was transferred in the dry load cell as a thin layer at the bottom of the cell. That thin layer was then covered with stationary phase until reaching a final mass of $1000 \mathrm{mg}$ and the cell was closed with a metallic sinter. The dry load was then directly connected to the Rheodyne ${ }^{\circledR}$ valve (Queiroz et al., 2019). According to UV signals, 33 fractions were collected. All the fractions were then analyzed by UHPLC-UV-ELSD-QDa and tested in the Wnt inhibition assay to localize bioactive fractions.

\section{Micro UHPLC-PDA Purification of the Active Fraction F19}

Separation was performed on a Waters ${ }^{\circledR}$ Acquity UPLC system (Waters ${ }^{\circledR}$, Milford, MA, United States) equipped with a UV-Vis programmable detector and an autosampler with a $2 \mu \mathrm{L}$ loop. Data acquisition, data handling, and instrument control were performed with Empower Software (Waters ${ }^{\circledR}$ ). The separation analyses of fraction F19 were performed on an Acquity BEH phenyl column $(2.1 \times 30 \mathrm{~mm} ; 1.7 \mu \mathrm{m})$ using a mobile phase consisting of water $(\mathrm{A})$ and acetonitrile (B), both with $0.1 \%$ FA. The separation was conducted with an isocratic mode: $5 \%$ of $B$ during $15 \mathrm{~min}$. The temperatures in the autosampler and column oven were, respectively, set at 10 and $40^{\circ} \mathrm{C}$. UV data were acquired at $210 \mathrm{~nm}$ with a time constant set at $100 \mathrm{~ms}$ and a data sampling rate at 20 points $/ \mathrm{s}$. The flow rate was set at $300 \mu \mathrm{L} / \mathrm{min}$. The fraction was concentrated at $4 \mathrm{mg} / \mathrm{ml}$ in ACN. 75 injections of $2 \mu \mathrm{L}$ were performed. Three peaks were collected based on the time frame by which their UV signals were received. The collection for the first peak was set from 5.67 to $6.39 \mathrm{~min}$, the second one from 7.09 to $7.91 \mathrm{~min}$, and third one from 9.05 to $10.12 \mathrm{~min}$. This allowed yielding $94 \mu \mathrm{g}$ of peak 1 (compound 10), $83 \mu \mathrm{g}$ of peak 2 (compound 11 ), and $30 \mu \mathrm{g}$ of peak 3 (compound 22 ). The reproducibility of the 75 injections can be accessed in Supplementary Figure 5.

\section{Description of the Isolated Compounds}

(Z)-3-((2R,3R,6R)-3-Hydroxy-6-((R)-1-hydroxyethyl)-3,6-dihydro2H-pyran-2-yl)acrylamide (1) (F6). [a $]_{D}^{25} 14.14$ (c. 0.1, MeOH); $\mathrm{UV}(\mathrm{MeOH}) \lambda_{\max } 205$ (3.94), 321 (2.32) nm. ${ }^{1} \mathrm{H}$ NMR (MeOD, $600 \mathrm{MHz}) \delta 1.19(3 \mathrm{H}, \mathrm{d}, J=6.4 \mathrm{~Hz}, \mathrm{H}-8), 3.71(1 \mathrm{H}, p, J=6.4,5.8 \mathrm{~Hz}$, $\mathrm{H}-7), 4.04(1 \mathrm{H}, \mathrm{dtd}, J=5.8,2.3,2.0,1.2 \mathrm{~Hz}, \mathrm{H}-2), 4.17(1 \mathrm{H}, \mathrm{dd}, J=$ $5.8,2.8 \mathrm{~Hz}, \mathrm{H}-6), 4.74(1 \mathrm{H}, \mathrm{dtd}, J=5.8,2.8,2.0,1.2 \mathrm{~Hz} \mathrm{H}-5), 6.10$ $(1 \mathrm{H}, \mathrm{ddd}, J=10.4,5.2,2.3 \mathrm{~Hz}, \mathrm{H}-4), 6.18(1 \mathrm{H}, \mathrm{d}, J=9.8 \mathrm{~Hz}, \mathrm{H}-2$ '), $6.32(1 \mathrm{H}, \mathrm{dt}, J=10.4,1.2 \mathrm{~Hz}, \mathrm{H}-3), 7.00(1 \mathrm{H}, \mathrm{dd}, J=9.8,5.8 \mathrm{~Hz}, \mathrm{H}-$ 1 '); ${ }^{13} \mathrm{C}$ NMR (MeOD, $\left.151 \mathrm{MHz}\right) \delta 18.8(\mathrm{C}-8), 66.2$ (C-6), $69.9(\mathrm{C}-$ 7), 71.5 (C-5), 80.6 (C-2), 123.3 (C-4), 124.8 (C-2'), 135.0 (C-3), 142.7 (C-1'), 165.4 (C-3'). ESI(+)-HRMS m/z 214.1071 [M + H] $]^{+}$ (calcd. for $\mathrm{C}_{10} \mathrm{H}_{16} \mathrm{NO}_{4}{ }^{+}, 214.1074, \Delta \mathrm{ppm}=1.40$ ). For NMR spectra, see Supplementary Figures 6-11.

Aconitate B (6-methyl ester trans-aconitate) (2) (F7). $\mathrm{UV}(\mathrm{MeOH}) \lambda_{\max } 209$ (3.49) nm. ${ }^{1} \mathrm{H}$ NMR (MeOD, $600 \mathrm{MHz}$ ) 
$\delta 3.81(3 \mathrm{H}, \mathrm{s}, \mathrm{H}-7), 3.88$ (2H, s, H-4), $6.91(1 \mathrm{H}, \mathrm{s}, \mathrm{H}-2)$; 13C NMR (MeOD, $151 \mathrm{MHz}) \delta 34.0$ (C-4), 53.1 (C-7), 131.7 (C-2), 139.9 (C-3), 168.2 (C-1, C-6), 173.8 (C-5). ESI(+)-HRMS m/z 189.0394 $[\mathrm{M}+\mathrm{H}]^{+}$(calcd. for $\left.\mathrm{C}_{7} \mathrm{H}_{9} \mathrm{O}_{6}{ }^{+}, 189.0394, \Delta \mathrm{ppm}=0.00\right)$. For NMR spectra, see Supplementary Figures 19-24 (Cai et al., 2001).

(3R,4R,Z)-4-Hydroxy-1-((2S,3S)-3-hydroxy-6-oxo-3,6-dihydro2H-pyran-2-yl)pent-1-en-3-yl acetate (3) (F8). [a] $]_{D}^{25} 9.98$ (c. 0.1, $\mathrm{MeOH}) ; \mathrm{UV}(\mathrm{MeOH}) \lambda_{\max } 205$ (3.99), sh 264 (3.37), 336 (3.25) nm. ${ }^{1} \mathrm{H}$ NMR (DMSO-d6, $\left.600 \mathrm{MHz}\right) \delta 1.05(3 \mathrm{H}, \mathrm{d}, J=6.4 \mathrm{~Hz}, \mathrm{H}-5$ '), $2.01\left(3 \mathrm{H}, \mathrm{s}, \mathrm{H}-7^{\prime}\right), 3.77$ (1H, qdd, $J=6.4,5.3,3.1 \mathrm{~Hz}, \mathrm{H}-4$ '), $4.02(1 \mathrm{H}$, ddd, $J=7.1,5.6,2.0 \mathrm{~Hz}, \mathrm{H}-5), 4.87(1 \mathrm{H}, \mathrm{d}, J=5.3 \mathrm{~Hz}, \mathrm{OH} 4$ '), 5.25 $(1 \mathrm{H}, \mathrm{dt}, J=9.2,2.0,1.1 \mathrm{~Hz}, \mathrm{H}-6), 5.29\left(1 \mathrm{H}, \mathrm{dd}, J=9.3,3.1 \mathrm{~Hz}, \mathrm{H}-3^{\prime}\right)$, $5.60(1 \mathrm{H}, \mathrm{d}, J=7.1 \mathrm{~Hz}, \mathrm{OH}), 5.71(1 \mathrm{H}, \mathrm{ddd}, J=11.1,9.3,1.1 \mathrm{~Hz}, \mathrm{H}-$ 2'), $5.90(1 \mathrm{H}, \mathrm{t}, J=11.1,9.2 \mathrm{~Hz}, \mathrm{H}-1$ '), $6.03(1 \mathrm{H}, \mathrm{d}, J=9.8 \mathrm{~Hz}, \mathrm{H}-3)$, $7.07(1 \mathrm{H}, \mathrm{dd}, J=9.8,5.6 \mathrm{~Hz}, \mathrm{H}-4) ;{ }^{13} \mathrm{C}$ NMR (DMSO-d6, $\left.151 \mathrm{MHz}\right)$ $\delta 18.4$ (C-5'), 20.7 (C-7'), 60.8 (C-5), 66.8 (C-4'), 73.4 (C-3'), 76.1 (C-6), 121.1 (C-3), 128.2 (C-1'), 129.7 (C-2'), 146.1 (C-4), 162.9 (C2), 169.4 (C-6'). ESI(+)-HRMS m/z $257.1020[\mathrm{M}+\mathrm{H}]^{+}$(calcd. for $\left.\mathrm{C}_{12} \mathrm{H}_{17} \mathrm{O}_{6}{ }^{+}, 257.1020, \Delta \mathrm{ppm}=0.00\right)$. For NMR spectra, see Supplementary Figures 25-29.

(2Z,6Z)-4,5,8,9-Tetrahydroxydeca-2,6-dienamide (4) (F9). $[a]_{D}^{25} 32.40$ (c. $\left.0.08, \mathrm{MeOH}\right) ; \mathrm{UV}(\mathrm{MeOH}) \lambda_{\max } 206$ (2.65), sh 266 (1.93), 343 (1.85) nm. ${ }^{1} \mathrm{H}$ NMR (MeOD, $\left.600 \mathrm{MHz}\right) \delta 1.24$ $(3 \mathrm{H}, \mathrm{d}, J=6.5 \mathrm{~Hz}, \mathrm{H}-10), 2.05$ (3H, s, H-12), 4.18 (1H, dd, $J=5.6$, $2.9 \mathrm{~Hz}, \mathrm{H}-4), 4.46(1 \mathrm{H}$, ddd, $J=8.3,5.0,1.2 \mathrm{~Hz}, \mathrm{H}-8), 4.90(1 \mathrm{H}$, $\mathrm{dd}, J=6.5,5.0 \mathrm{~Hz}, \mathrm{H}-9), 5.33(1 \mathrm{H}, \mathrm{ddd}, J=9.1,2.9,1.0 \mathrm{~Hz}, \mathrm{H}-5)$, $5.78(1 \mathrm{H}, \mathrm{ddd}, J=11.3,8.3,1.0 \mathrm{~Hz}, \mathrm{H}-7), 5.93(1 \mathrm{H}$, ddd, $J=11.3$, 9.1, $1.2 \mathrm{~Hz}, \mathrm{H}-6), 6.09$ (1H, d, $J=9.8 \mathrm{~Hz}, \mathrm{H}-2), 7.07$ (1H, dd, $J=$ 9.8, 5.6 Hz, H-3); ${ }^{13} \mathrm{C}$ NMR (MeOD, $\left.151 \mathrm{MHz}\right) \delta 15.6(\mathrm{C}-10)$, 21.2 (C-12), 63.4 (C-4), 70.7 (C-8), 74.4 (C-9), 78.3 (C-5), 122.8 (C-2), 127.7 (C-6), 135.4 (C-7), 147.1 (C-3), 165.9 (C-1), 172.6 (C-11). ESI(+)-HRMS $m / z$ 274.1291 $[\mathrm{M}+\mathrm{H}]^{+}$(calcd. for $\left.\mathrm{C}_{12} \mathrm{H}_{20} \mathrm{NO}_{6}{ }^{+}, 274.1285, \Delta \mathrm{ppm}=2.15\right)$. For NMR spectra, see Supplementary Figures 30-35.

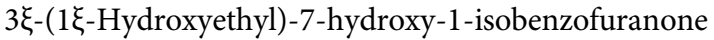

(F10). UV(MeOH) $\lambda_{\max } 207$ (3.64), sh 240 (2.98), 303 (2.88) nm. Isomer 1: ${ }^{1} \mathrm{H}$ NMR (MeOD, $\left.600 \mathrm{MHz}\right) \delta 1.26(3 \mathrm{H}, \mathrm{d}, J=6.5$ $\left.\mathrm{Hz}, \mathrm{H}-2{ }^{\prime}\right), 4.20$ (1H, qd, $\left.J=6.5,3.1 \mathrm{~Hz}, \mathrm{H}-1^{\prime}\right), 5.37$ (1H, d, $J=3.1$ $\mathrm{Hz}, \mathrm{H}-3), 6.90(1 \mathrm{H}, \mathrm{d}, J=7.8 \mathrm{~Hz}, \mathrm{H}-6), 7.05(1 \mathrm{H}, \mathrm{d}, J=7.8 \mathrm{~Hz}, \mathrm{H}-$ 4), $7.54(1 \mathrm{H}, \mathrm{t}, J=7.8 \mathrm{~Hz}, \mathrm{H}-5) ;{ }^{13} \mathrm{C} \mathrm{NMR}(\mathrm{MeOD}, 151 \mathrm{MHz}) \delta$ 18.9 (C-2'), 68.7 (C-1'), 85.2 (C-3), 113.6 (C-8), 114.7 (C-4), 116.8 (C-6), 137.4 (C-5), 151.0 (C-9), 158.2 (C-7), 172.0 (C-1). Isomer 2: ${ }^{1} \mathrm{H}$ NMR (MeOD, $\left.600 \mathrm{MHz}\right) \delta 1.18(3 \mathrm{H}, \mathrm{d}, J=6.5 \mathrm{~Hz}, \mathrm{H}-2$ '), $4.05\left(1 \mathrm{H}, \mathrm{qd}, J=6.5,4.5 \mathrm{~Hz}, \mathrm{H}-1^{\prime}\right), 5.34(1 \mathrm{H}, \mathrm{d}, J=4.5 \mathrm{~Hz}, \mathrm{H}-3)$, $6.88(1 \mathrm{H}, \mathrm{d}, J=7.8 \mathrm{~Hz}, \mathrm{H}-6), 7.07(1 \mathrm{H}, \mathrm{d}, J=7.8 \mathrm{~Hz}, \mathrm{H} 4), 7.54$ $(1 \mathrm{H}, \mathrm{t}, J=7.8 \mathrm{~Hz}, \mathrm{H}-5) ;{ }^{13} \mathrm{C} \mathrm{NMR}(\mathrm{MeOD}, 151 \mathrm{MHz}) \delta 18.0(\mathrm{C}-$ 2'), 69.7 (C-1'), 85.7 (C-3), 113.1 (C-8), 115.0 (C-4), 116.9 (C-6), 137.4 (C-5), 150.6 (C-9), 158.3 (C-7), 171.9 (C-1). ESI(+)-HRMS $\mathrm{m} / z 195.0652[\mathrm{M}+\mathrm{H}]^{+}$(calcd. for $\mathrm{C}_{10} \mathrm{H}_{11} \mathrm{O}_{4}{ }^{+}, 195.0652, \Delta \mathrm{ppm}=$ 0.15). For NMR spectra, see Supplementary Figures 36-41 (Rahman and Gray, 2005).

(2Z,4Z,8E)-6,7-Dihydroxydeca-2,4,8-trienoic acid (6) (F11). $\mathrm{UV}(\mathrm{MeOH}) \lambda_{\max } 205$ (3.61), sh 225 (3.51), 257 (3.42) nm. ${ }^{1} \mathrm{H}$ NMR (MeOD, $600 \mathrm{MHz}) \delta 1.67(3 \mathrm{H}, \mathrm{dd}, J=6.5,1.5 \mathrm{~Hz}, \mathrm{H}-10)$, $3.92(1 \mathrm{H}, \mathrm{t}, J=7.1 \mathrm{~Hz}, \mathrm{H}-7), 4.45(1 \mathrm{H}, \mathrm{dd}, J=9.1,7.1 \mathrm{~Hz}, \mathrm{H}-6)$, $5.45(1 \mathrm{H}, \mathrm{ddq}, J=15.2,7.1,1.5 \mathrm{~Hz}, \mathrm{H}-8), 5.72(1 \mathrm{H}, \mathrm{dq}, J=15.2,6.5$ Hz, H-9), 5.74 (1H, d, $J=11.5 \mathrm{~Hz}, \mathrm{H}-2), 5.75$ (1H, dd, $J=11.5,9.1$
$\mathrm{Hz}, \mathrm{H}-5), 7.01(1 \mathrm{H}, \mathrm{t}, J=11.5 \mathrm{~Hz}, \mathrm{H}-3), 7.32(1 \mathrm{H}, \mathrm{t}, J=11.5 \mathrm{~Hz}$, $\mathrm{H}-4) ;{ }^{13} \mathrm{C}$ NMR (MeOD, $\left.151 \mathrm{MHz}\right) \delta 18.0$ (C-10), 71.5 (C-6), 76.9 (C-7), 120.8 (C-2), 127.4 (C-4), 129.5 (C-9), 131.1 (C-8), 139.0 (C-5), 139.6 (C-3), 170.0 (C-1). ESI(+)-HRMS m/z 199.0964 [M + $\mathrm{H}]^{+}$(calcd. for $\mathrm{C}_{10} \mathrm{H}_{15} \mathrm{O}_{4}{ }^{+}, 199.0965, \Delta \mathrm{ppm}=0.51$ ). For NMR spectra, see Supplementary Figures 42-47.

(+)-(3R,4S)-4,5-Dihydroxymellein (7) (F13). $\quad[a]_{D}^{25} 27.62$ (c.0.115, MeOH); UV(MeOH) $\lambda_{\max } 213$ (4.01), 222 (4.02) nm. ${ }^{1} \mathrm{H}$ NMR (MeOD, $\left.600 \mathrm{MHz}\right) \delta 1.28(3 \mathrm{H}, \mathrm{d}, J=6.8 \mathrm{~Hz}, \mathrm{H}-11), 4.85$ (1H, overlapped, H-3), $4.94(1 \mathrm{H}, \mathrm{d}, J=2.5 \mathrm{~Hz}, \mathrm{H}-4), 6.85(1 \mathrm{H}, \mathrm{d}$, $J=9.0 \mathrm{~Hz}, \mathrm{H}-7), 7.11(1 \mathrm{H}, \mathrm{d}, J=9.0 \mathrm{~Hz}, \mathrm{H}-6) ;{ }^{13} \mathrm{C} \mathrm{NMR}(\mathrm{MeOD}$, $151 \mathrm{MHz}) \delta 18.1$ (C-11), 64.4 (C-4), 82.7 (C-3), 108.1 (C-9), 119.1 (C-7), 124.2 (C-10), 126.2 (C-6), 148.8 (C-5), 156.1 (C-8), 169.9 (C-1). ESI(+)-HRMS $m / z 211.0601[\mathrm{M}+\mathrm{H}]^{+}$(calcd. for $\left.\mathrm{C}_{10} \mathrm{H}_{11} \mathrm{O}_{5}^{+}, 211.0601, \Delta \mathrm{ppm}=0.10\right)$. For NMR spectra, see Supplementary Figures 48-53 (Meepagala et al., 2018).

(-)-(3R,4R)-4-Hydroxymellein (8) (F14). [a $]_{D}^{25}-17.06$ (c.0.18, $\mathrm{MeOH}) ; \mathrm{UV}(\mathrm{MeOH}) \lambda_{\max } 211$ (3.88) nm. ${ }^{1} \mathrm{H}$ NMR (MeOD, $600 \mathrm{MHz}) \delta 1.52(3 \mathrm{H}, \mathrm{d}, J=6.6 \mathrm{~Hz}, \mathrm{H}-11), 4.56(1 \mathrm{H}, \mathrm{d}, J=2.1 \mathrm{~Hz}$, $\mathrm{H}-4), 4.72(1 \mathrm{H}, \mathrm{qd}, J=6.6,2.1 \mathrm{~Hz}, \mathrm{H}-3), 6.97$ (2H, m, H-5, H-7), $7.56(1 \mathrm{H}, \mathrm{dd}, J=8.4,7.4 \mathrm{~Hz}, \mathrm{H}-6) ;{ }^{13} \mathrm{C} \mathrm{NMR}(\mathrm{MeOD}, 151 \mathrm{MHz}) \delta$ 16.3 (C-11), 67.7 (C-4), 80.0 (C-3), 108.4 (C-9), 118.4 (C-7), 119.8 (C-5), 137.7 (C-6), 143.2 (C-10), 162.9 (C-8), 171.0 (C-1). ESI(+)HRMS $m / z 195.0654[\mathrm{M}+\mathrm{H}]^{+}$(calcd. for $\mathrm{C}_{10} \mathrm{H}_{11} \mathrm{O}_{4}{ }^{+}, 195.0652$, $\Delta \mathrm{ppm}=1.03)$. For NMR spectra, see Supplementary Figures 54-59 (Djoukeng et al., 2009).

(-)-(3R,4S)-4-Hydroxymellein (9) (F16). [a $]_{D}^{25}-6.83$ (c.0.1, $\mathrm{MeOH}) ; \mathrm{UV}(\mathrm{MeOH}) \lambda_{\max } 209$ (3.57) nm. ${ }^{1} \mathrm{H}$ NMR (MeOD, $600 \mathrm{MHz}) \delta 1.47(3 \mathrm{H}, \mathrm{d}, J=6.3 \mathrm{~Hz}, \mathrm{H}-11), 4.56(2 \mathrm{H}, \mathrm{m}, \mathrm{H}-3, \mathrm{H}-$ 4), $6.94(1 \mathrm{H}, \mathrm{dd}, J=8.4,1.0 \mathrm{~Hz}, \mathrm{H}-7), 7.08(1 \mathrm{H}, \mathrm{dt}, J=7.5,1.0 \mathrm{~Hz}$, $\mathrm{H}-5), 7.57(1 \mathrm{H}$, dd, $J=8.4,7.5 \mathrm{~Hz}, \mathrm{H}-6) ;{ }^{13} \mathrm{C} \mathrm{NMR}(\mathrm{MeOD}$, $151 \mathrm{MHz}) \delta 18.2$ (C-11), 69.5 (C-4), 81.6 (C-3), 108.0 (C-9), 117.7 (C-5), 117.8 (C-7), 137.8 (C-6), 144.1 (C-10), 162.9 (C-8), 170.2 (C-1). ESI(+)-HRMS $m / z 195.0652[\mathrm{M}+\mathrm{H}]^{+}$(calcd. for $\left.\mathrm{C}_{10} \mathrm{H}_{11} \mathrm{O}_{4}{ }^{+}, 195.0652, \Delta \mathrm{ppm}=0.00\right)$. For NMR spectra, see Supplementary Figures 60-65 (Cimmino et al., 2017).

(3S,4R)-3-Carboxy-2-methylene-heptan-4-olide (10) (F19). ${ }^{1} \mathrm{H}$ NMR (MeOD, $\left.600 \mathrm{MHz}\right) \delta 0.99(3 \mathrm{H}, \mathrm{t}, J=7.4 \mathrm{~Hz}, \mathrm{H}-7)$, $1.48(2 \mathrm{H}, \mathrm{m}, \mathrm{H}-6), 1.72(2 \mathrm{H}, \mathrm{m}, \mathrm{H}-5), 3.72(1 \mathrm{H}, \mathrm{dt}, J=5.6,2.8 \mathrm{~Hz}$, $\mathrm{H}-3), 4.80(1 \mathrm{H}, \mathrm{dt}, J=6.7,5.6 \mathrm{~Hz}, \mathrm{H}-4), 6.00(1 \mathrm{H}, \mathrm{d}, J=2.8 \mathrm{~Hz}, \mathrm{H}-$ 8 '), 6.32 (1H, d, $J=2.8 \mathrm{~Hz}, \mathrm{H}-8$ '); ${ }^{13} \mathrm{C}$ NMR (MeOD, $\left.151 \mathrm{MHz}\right) \delta$ 14.0 (7), 19.3 (6), 38.7 (5), 81.0 (4), 125.2 (8), 135.6 (2), 170.6 (1), 172.5 (9). ESI(-)-HRMS $m / z$ 183.0661 $[\mathrm{M}-\mathrm{H}]^{-}$(calcd. for $\left.\mathrm{C}_{9} \mathrm{H}_{11} \mathrm{O}_{4}{ }^{-}, 183.0663, \Delta \mathrm{ppm}=1.09\right)$. For NMR spectra, see Supplementary Figures 68-72 (He et al., 2004).

Decumbic acid (11) (F19). ${ }^{1} \mathrm{H}$ NMR (MeOD, $\left.600 \mathrm{MHz}\right) \delta 0.96$ $(3 \mathrm{H}, \mathrm{t}, J=7.4 \mathrm{~Hz}, \mathrm{H}-7), 1.48$ (2H, m, H-6), 1.59 (1H, m, H-5”), 2.09 $\left(1 \mathrm{H}, \mathrm{m}, \mathrm{H}-5^{\prime}\right), 2.13(3 \mathrm{H}, \mathrm{d}, J=2.1 \mathrm{~Hz}, \mathrm{H}-8), 5.15(1 \mathrm{H}, \mathrm{m}, \mathrm{H}-4) ;{ }^{13} \mathrm{C}$ NMR (MeOD, $151 \mathrm{MHz}) \delta 10.6(8), 14.1$ (7), 19.1 (6), 35.7 (5), 83.0 (4), 136.9 (2), 151.2 (3), 165.0 (9), 175.3 (1). ESI(-)-HRMS m/z $183.0660[\mathrm{M}-\mathrm{H}]^{-}$(calcd. for $\mathrm{C}_{9} \mathrm{H}_{11} \mathrm{O}_{4}{ }^{-}, 183.0663, \Delta \mathrm{ppm}=1.53$ ). For NMR spectra, see Supplementary Figures 68-71,73 (He et al., 2004).

Decumbic acid B (12) (F20). [a $]_{D}^{25} 5.03$ (c.0.12, MeOH). ${ }^{1} \mathrm{H}$ NMR (MeOD, $600 \mathrm{MHz}) \delta 0.98(3 \mathrm{H}, \mathrm{t}, J=7.4 \mathrm{~Hz}, \mathrm{H}-7), 1.29(3 \mathrm{H}$, d, $J=7.1 \mathrm{~Hz}, \mathrm{H}-8), 1.46$ (1H, m, H-6”), 1.55 (1H, m, H-6'), 1.70 $\left(1 \mathrm{H}, \mathrm{m}, \mathrm{H}-5^{\prime \prime}\right), 1.82\left(1 \mathrm{H}, \mathrm{m}, \mathrm{H}-5^{\prime}\right), 2.70$ (1H, dd, $J=11.4,9.4 \mathrm{~Hz}$, 
H-3), 2.99 (1H, dq, $J=11.4,7.1 \mathrm{~Hz}, \mathrm{H}-2), 4.49(1 \mathrm{H}, \mathrm{td}, J=9.4,8.4$, $4.0 \mathrm{~Hz}, \mathrm{H}-4) ;{ }^{13} \mathrm{C}$ NMR (MeOD, $\left.151 \mathrm{MHz}\right) \delta 14.1$ (C-7), 14.6 (C8), 19.9 (C-6), 38.0 (C-5), 41.1 (C-2), 55.5 (C-3), 81.4 (C-4), 174.1 (C-9), 179.7 (C-1). ESI(-)-HRMS $m / z 185.0818$ [M-H] ${ }^{-}$(calcd. for $\left.\mathrm{C}_{9} \mathrm{H}_{14} \mathrm{O}_{4}, 185.0819, \Delta \mathrm{ppm}=0.54\right)$. For NMR spectra, see Supplementary Figures 75-80 (Zhou et al., 2016).

(-)-(R)-Mellein (13) (F22). [a $]_{D}^{25}-16.28$ (c.0.08, MeOH); $\mathrm{UV}(\mathrm{MeOH}) \lambda_{\max } 208$ (3.78), 236 (3.52) nm. ${ }^{1} \mathrm{H}$ NMR (MeOD, $600 \mathrm{MHz}) \delta 1.49(3 \mathrm{H}, \mathrm{d}, J=6.3 \mathrm{~Hz}, \mathrm{H}-11), 2.92(1 \mathrm{H}, \mathrm{dd}, J=16.4$, $11.3 \mathrm{~Hz}, \mathrm{H}-4$ ') $3.03(1 \mathrm{H}, \mathrm{dd}, J=16.4,3.3 \mathrm{~Hz}, \mathrm{H}-4$ '), $4.75(1 \mathrm{H}$, dqd, $J=11.3,6.3,3.3 \mathrm{~Hz}, \mathrm{H}-3), 6.78(1 \mathrm{H}, \mathrm{d}, J=7.3 \mathrm{~Hz}, \mathrm{H}-5), 6.85$ $(1 \mathrm{H}, \mathrm{d}, J=8.4 \mathrm{~Hz}, \mathrm{H}-7), 7.45(1 \mathrm{H}, \mathrm{dd}, J=8.4,7.3 \mathrm{~Hz}, \mathrm{H}-6) ;{ }^{13} \mathrm{C}$ NMR (MeOD, $151 \mathrm{MHz}) \delta 20.9$ (C-11), 35.2 (C-4), 77.8 (C-3), 109.3 (C-9), 116.7 (C-7), 119.3 (C-5), 137.4 (C-6), 141.6 (C-10), $163.2(\mathrm{C}-8), 171.6(\mathrm{C}-1)$. ESI(+)-HRMS $m / z 179.0702[\mathrm{M}+\mathrm{H}]^{+}$ (calcd. for $\mathrm{C}_{10} \mathrm{H}_{11} \mathrm{O}_{3}{ }^{+}, 179.0703, \Delta \mathrm{ppm}=0.56$ ). For NMR spectra, see Supplementary Figures 81-86 (Djoukeng et al., 2009).

(2R)-Butylitaconic acid (14) (F24). [a $]_{D}^{25}-1.61$ (c.0.14, MeOH); ${ }^{1} \mathrm{H}$ NMR (MeOD, $\left.600 \mathrm{MHz}\right) \delta 0.91(3 \mathrm{H}, \mathrm{t}, J=7.1 \mathrm{~Hz}, \mathrm{H}-8), 1.32$ (2H, m, H-6), 1.35 (2H, m, H-7), 1.69 (1H, m, H-5”), 1.86 (1H, m, H-5'), 3.37 (1H, t, J= 7.7 Hz, H-2), 5.60 (1H, s, H-9”), $6.14(1 \mathrm{H}, \mathrm{s}$, $\mathrm{H}-9$ '); ${ }^{13} \mathrm{C}$ NMR (MeOD, $\left.151 \mathrm{MHz}\right) \delta 14.3$ (C-8), 23.5 (C-7), 31.0 (C-6), 32.1 (C-5), 49.8 (C-2), 125.4 (C-9), 142.7 (C-3), 172.0 (C4), $178.5(\mathrm{C}-1)$. ESI(+)-HRMS m/z $187.0965[\mathrm{M}+\mathrm{H}]^{+}$(calcd. for $\left.\mathrm{C}_{9} \mathrm{H}_{15} \mathrm{O}_{4}{ }^{+}, 187.0965, \Delta \mathrm{ppm}=0.00\right)$. For NMR spectra, see Supplementary Figures 87-92 (Nakahashi et al., 2009).

(+)-(R)-CJ-12,372 (15) (F26). [a $]_{D}^{25} 2.0$ (c.0.09, MeOH); ${ }^{1} \mathrm{H}$ NMR (MeOD, $600 \mathrm{MHz}) \delta 1.89(1 \mathrm{H}, \mathrm{m}, \mathrm{H}-2 \mathrm{~b}), 2.05(1 \mathrm{H}, \mathrm{m}, \mathrm{H}-$ 2a), $2.10(1 \mathrm{H}, \mathrm{m}, \mathrm{H}-3 \mathrm{~b}), 2.35(1 \mathrm{H}, \mathrm{ddd}, J=14.6,11.8,2.9 \mathrm{~Hz}, \mathrm{H}-$ 3a), $5.10(1 \mathrm{H}, \mathrm{t}, J=4.5 \mathrm{~Hz}, \mathrm{H}-1), 6.77(1 \mathrm{H}, \mathrm{d}, J=8.8 \mathrm{~Hz}, \mathrm{H}-6), 6.85$ $(1 \mathrm{H}, \mathrm{d}, J=8.8 \mathrm{~Hz}, \mathrm{H}-7), 6.94\left(1 \mathrm{H}, \mathrm{d}, J=7.5 \mathrm{~Hz}, \mathrm{H}-7^{\prime}\right), 6.98(1 \mathrm{H}, \mathrm{d}$, $\left.J=7.5 \mathrm{~Hz}, \mathrm{H}-2^{\prime}\right), 7.46\left(1 \mathrm{H}, \mathrm{t}, J=7.5 \mathrm{~Hz}, \mathrm{H}-6^{\prime}\right), 7.47(1 \mathrm{H}, \mathrm{t}, J=7.9$ $\left.\mathrm{Hz}, \mathrm{H}-3^{\prime}\right), 7.54\left(1 \mathrm{H}, \mathrm{d}, J=7.5 \mathrm{~Hz}, \mathrm{H}-5^{\prime}\right), 7.56(1 \mathrm{H}, \mathrm{d}, J=7.5 \mathrm{~Hz}, \mathrm{H}-$ 4 ) ; ${ }^{13} \mathrm{C}$ NMR (MeOD, $\left.151 \mathrm{MHz}\right) \delta 27.3$ (C-3), 28.2 (C2), 64.0 (C1), 110.5 (C-2', C-7'), 114.6 (C-9'), 118.5 (C-6), 118.6 (C-7), 121.5 (C-4', C-5'), 127.1 (C-9), 127.3 (C-10), 128.2 (C-3', C-6'), 135.3 (C-10'), 148.4 (C-1', C-8'), 149.6 (C-8), 150.1 (C-5). ESI(+)HRMS $m / z 337.1076[\mathrm{M}+\mathrm{H}]^{+}$(calcd. for $\mathrm{C}_{20} \mathrm{H}_{17} \mathrm{O}_{5}{ }^{+}$, $337.1071, \Delta \mathrm{ppm}=1.48)$. For NMR spectra, see Supplementary Figures 93-96 (Sakemi et al., 1995).

(+)-(R)-Palmarumycin EG1 (16) (F29). $[a]_{D}^{25} 92.20$ (c.0.02, $\mathrm{MeOH}) ; \mathrm{UV}(\mathrm{MeOH}) \lambda_{\max } 226$ (5.07), sh 207(4.94) nm. ${ }^{1} \mathrm{H}$ NMR (MeOD, $600 \mathrm{MHz}) \delta 1.91(1 \mathrm{H}, \mathrm{tt}, J=14.0,3.1 \mathrm{~Hz}, \mathrm{H}-$ 2b), $2.08(1 \mathrm{H}, \mathrm{dq}, J=14.0,3.1 \mathrm{~Hz}, \mathrm{H}-2 \mathrm{a}), 2.18(1 \mathrm{H}, \mathrm{dt}, J=14.0,3.1$ $\mathrm{Hz}, \mathrm{H}-3 \mathrm{~b}), 2.25$ (1H, td, $J=14.0,3.1 \mathrm{~Hz}, \mathrm{H}-3 \mathrm{a}), 3.44(3 \mathrm{H}, \mathrm{s}, \mathrm{OMe})$, $4.71(1 \mathrm{H}, \mathrm{t}, J=3.1 \mathrm{~Hz}, \mathrm{H}-1), 6.79(1 \mathrm{H}, \mathrm{d}, J=8.7 \mathrm{~Hz}, \mathrm{H}-6), 6.86$ $(1 \mathrm{H}, \mathrm{d}, J=8.7 \mathrm{~Hz}, \mathrm{H}-7), 6.92(1 \mathrm{H}, \mathrm{d}, J=7.5 \mathrm{~Hz}, \mathrm{H}-7$ '), $6.98(1 \mathrm{H}, \mathrm{d}$, $\left.J=7.5 \mathrm{~Hz}, \mathrm{H}-2^{\prime}\right), 7.46\left(0 \mathrm{H}, \mathrm{t}, J=7.5 \mathrm{~Hz}, \mathrm{H}-6^{\prime}\right), 7.47(1 \mathrm{H}, \mathrm{t}, J=7.5$ $\left.\mathrm{Hz}, \mathrm{H}-3^{\prime}\right), 7.54\left(1 \mathrm{H}, \mathrm{d}, J=7.5 \mathrm{~Hz}, \mathrm{H}-5^{\prime}\right), 7.56(1 \mathrm{H}, \mathrm{d}, J=7.5 \mathrm{~Hz}, \mathrm{H}-$ 4 '); ${ }^{13} \mathrm{C}$ NMR (MeOD, $\left.151 \mathrm{MHz}\right) \delta 24.1$ (C-2), 27.0 (C-3), 57.1 (OMe), 71.8 (C-1), 103.7 (C-4), 110.8 (C-7'), 110.8 (C-2'), 115.0 (C-9'), 118.9 (C-7), 119.2 (C-6), 121.6 (C-5'), 122.0 (C-4'), 122.0 (C-10), 125.7 (C-9), 128.5 (C-3'), 128.6 (C-6'), 135.7 (C-10'), 148.6 (C-1'), 149.1 (C-8'), 150.1 (C-8), 150.5 (C-5). ESI(+)-HRMS $m / z 351.1227[\mathrm{M}+\mathrm{H}]^{+}$(calcd. for $\mathrm{C}_{21} \mathrm{H}_{19} \mathrm{O}_{5}{ }^{+}, 351.1227, \Delta \mathrm{ppm}=$ 0.10). For NMR spectra, Supplementary Figures 97-102 (Macías-Rubalcava et al., 2014).
(R)-4-Methoxy-3,4-dihydro-2H-spiro[naphthalene-1,2'-naphtho [1,8-de][1,3]dioxin]-6-ol (17) (F32). [a] $]_{D}^{25} 47.9$ (c. 0.04, MeOH); $\mathrm{UV}(\mathrm{MeOH}) \lambda_{\max } 226$ (4.17), sh 214 (4.06) nm. ${ }^{1} \mathrm{H}$ NMR $(\mathrm{MeOD}, 600 \mathrm{MHz}) \delta 2.02(1 \mathrm{H}, \mathrm{m}, \mathrm{H}-2 \mathrm{~b}), 2.12(1 \mathrm{H}, \mathrm{m}, \mathrm{H}-2 \mathrm{a})$, $2.14(1 \mathrm{H}, \mathrm{m}, \mathrm{H}-3 \mathrm{~b}), 2.20(1 \mathrm{H}, \mathrm{m}, \mathrm{H}-3 \mathrm{a}), 3.47(3 \mathrm{H}, \mathrm{s}, \mathrm{OMe}), 4.73(1 \mathrm{H}$, $\mathrm{t}, J=3.2 \mathrm{~Hz}, \mathrm{H}-1), 6.85\left(1 \mathrm{H}, \mathrm{dd}, J=7.4,0.8 \mathrm{~Hz}, \mathrm{H}-7^{\prime}\right), 6.92(1 \mathrm{H}, \mathrm{dd}$, $J=7.4,0.9 \mathrm{~Hz}, \mathrm{H}-2$ ') $6.93(1 \mathrm{H}, \mathrm{dd}, J=6.8,2.3 \mathrm{~Hz}, \mathrm{H}-6), 7.26(1 \mathrm{H}, \mathrm{d}$, $J=2.3 \mathrm{~Hz}, \mathrm{H}-8), 7.27(1 \mathrm{H}, \mathrm{d}, J=6.8 \mathrm{~Hz}, \mathrm{H}-5), 7.43(1 \mathrm{H}, \mathrm{dd}, J=8.4$, $7.4 \mathrm{~Hz}, \mathrm{H}-6$ ') 7.45 (1H, dd, $\left.J=8.4,7.4 \mathrm{~Hz}, \mathrm{H}-3^{\prime}\right), 7.50$ (1H, dd, $J=$ 8.4, $\left.0.8 \mathrm{~Hz}, \mathrm{H}-5^{\prime}\right), 7.51$ (1H, dd, $J=8.4,0.9 \mathrm{~Hz}, \mathrm{H}-4$ '); ${ }^{13} \mathrm{C} \mathrm{NMR}$ (MeOD, $151 \mathrm{MHz}) \delta 23.8(\mathrm{C}-2), 26.1(\mathrm{C}-3), 56.8$ (OMe), $71.6(\mathrm{C}-1)$, 101.1 (C-4), 109.9 (C-2', C-7'), 114.5 (C-9'), 116.7 (C-6), 119.0 (C-8), 121.1 (C-4', C-5'), 128.2 (C-3', C-6'), 130.0 (C-5), 135.3 (C-10'), 148.9 (C-8'), 149.4 (C-1'). ESI(-)-HRMS m/z 333.1134 [M-H] ${ }^{-}$(calcd. for $\mathrm{C}_{21} \mathrm{H}_{17} \mathrm{O}_{4}^{+}$, 333.1132, $\left.\Delta \mathrm{ppm}=0.51\right)$. For NMR spectra, see Supplementary Figures 103-106.

(R)-(-)-5-Hydroxymellein (18) (F19). $[a]_{D}^{25}-31.0$ (c. 0.007, $\mathrm{MeOH}) ; \mathrm{UV}(\mathrm{MeOH}) \lambda_{\max } 224$ (5.3), sh 26(4.4), 351 (4.2)nm. ${ }^{1} \mathrm{H}$ NMR (MeOD, $\left.600 \mathrm{MHz}\right) \delta 1.50(3 \mathrm{H}, \mathrm{d}, J=6.3 \mathrm{~Hz}, \mathrm{H}-11), 2.62$ $(1 \mathrm{H}$, ddd, $J=16.9,11.3,0.9 \mathrm{~Hz}, \mathrm{H}-4 \mathrm{~b}), 3.17(1 \mathrm{H}, \mathrm{dd}, J=16.9,3.4$ $\mathrm{Hz}, \mathrm{H}-4 \mathrm{a}), 4.70(1 \mathrm{H}, \mathrm{dqd}, J=11.3,6.3,3.4 \mathrm{~Hz}, \mathrm{H}-3), 6.71(1 \mathrm{H}, \mathrm{dd}$, $J=8.9,0.9 \mathrm{~Hz}, \mathrm{H}-7), 7.02(1 \mathrm{H}, \mathrm{d}, J=8.9 \mathrm{~Hz}, \mathrm{H}-6) ;{ }^{13} \mathrm{C} \mathrm{NMR}$ (MeOD, $151 \mathrm{MHz}) \delta 21.1$ (C-11), 29.4 (C-4), 77.7 (C-3), 109.2 (C-9), 116.5 (C-7), 125.1 (C-6), 125.9 (C-10), 146.9 (C-5), 156.4 (C-8), 171.8 (C-1). ESI(+)-HRMS m/z $195.0652[\mathrm{M}+\mathrm{H}]^{+}$(calcd. for $\left.\mathrm{C}_{10} \mathrm{H}_{11} \mathrm{O}_{4}{ }^{+}, 195.0652, \Delta \mathrm{ppm}=0.00\right)$. For NMR spectra, see Supplementary Figures 68-71,74 (Salvatore et al., 2020).

\section{Preparation of the S- and $R-\alpha$-Methoxy- $\alpha-$ Trifluoromethylphenylacetyl Chloride Esters Derivatives $6 S$ and $6 R$ for Compound 1 (59)}

$R$-MTPA ester derivative: to a stirred solution of 1 (1, $1.3 \mathrm{mg}$, $0.0061 \mathrm{mmol})$ and dry deuterated pyridine-d5 $(19 \mu \mathrm{L}, 0.24 \mathrm{mmol}$, 39 equiv. $)$ in dry deuterochloroform $\mathrm{CDCl}_{3}(100 \mu \mathrm{L}$, [pyridine-d5] = $0.32 \mathrm{M})$ at room temperature, $(S)-(+)-\mathrm{MTPA}-\mathrm{Cl}(3 S, 16 \mu \mathrm{L}, 0.086$ mmol, 14 equiv.) was added under inert atmosphere (Argon). The reaction was left for $2 \mathrm{~h}$. The reaction mixture was then diluted in dry $\mathrm{CDCl}_{3}(0.6 \mathrm{ml})$ and submitted to ${ }^{1} \mathrm{H}-\mathrm{NMR}$ analysis. This gave the $R$-MTPA-methyl ester of 1 (34 mg) as a brown oil: ${ }^{1} \mathrm{H} \mathrm{NMR}\left(\mathrm{CDCl}_{3}\right.$, $600 \mathrm{MHz}) \delta 1.31(3 \mathrm{H}, \mathrm{d}, J=6.5 \mathrm{~Hz}, \mathrm{H}-8), 3.44(3 \mathrm{H}, \mathrm{d}, J=1.3 \mathrm{~Hz}$, OMe), $3.94(1 \mathrm{H}, \mathrm{dd}, J=5.9,2.9 \mathrm{~Hz}, \mathrm{H}-6), 4.17(1 \mathrm{H}, \mathrm{dq}, J=4.8,2.2 \mathrm{~Hz}$, $\mathrm{H}-2), 4.54(1 \mathrm{H}, \mathrm{dt}, J=5.2,2.9,2.2 \mathrm{~Hz}, \mathrm{H}-5), 5.12(1 \mathrm{H}, \mathrm{qd}, J=6.5,4.8$ $\mathrm{Hz}, \mathrm{H}-7), 5.91(1 \mathrm{H}, \mathrm{d}, J=10.3 \mathrm{~Hz}, \mathrm{H}-3), 6.03(1 \mathrm{H}$, ddd, $J=10.3,5.2$, $2.2 \mathrm{~Hz}, \mathrm{H}-4), 6.11(1 \mathrm{H}, \mathrm{d}, J=9.7 \mathrm{~Hz}, \mathrm{H}-2$ '), $6.71(1 \mathrm{H}, \mathrm{dd}, J=9.7,5.8$ $\mathrm{Hz}, \mathrm{H}-1$ '); ${ }^{13} \mathrm{C} \mathrm{NMR}\left(\mathrm{CDCl}_{3}, 151 \mathrm{MHz}\right) \delta 13.7$ (C-8), $54.3(\mathrm{OMe})$, 64.0 (C6), 68.1 (C-5), 72.6 (C-7), 74.9 (C-2), 122.4 (C-4), 123.6 (C-2'), 130.5 (C-3), 138.7 (C-1'). (Supplementary Figures 13-15). S-MTPA ester derivative: to a stirred solution of $1(1,1.3 \mathrm{mg}, 0.0061 \mathrm{mmol})$ and dry deuterated pyridine-d5 ( $19 \mu \mathrm{L}, 0.24 \mathrm{mmol}, 39$ equiv. $)$ in dry deuterochloroform $\mathrm{CDCl}_{3}(100 \mu \mathrm{L}$ [pyridine-d5] $=0.32 \mathrm{M})$ at room temperature, $(R)-(-)-\mathrm{MTPA}-\mathrm{Cl}(3 S, 18.3 \mu \mathrm{L}, 0.098 \mathrm{mmol}, 16$ equiv.) was added under inert atmosphere (Argon). The reaction was left for $2 \mathrm{~h}$. The reaction mixture was then diluted in dry $\mathrm{CDCl}_{3}(0.6 \mathrm{ml})$ and submitted to ${ }^{1} \mathrm{H}-\mathrm{NMR}$ analysis. This gave the $S$-MTPA-methyl ester of $1(19.9 \mathrm{mg})$ as a brown oil: ${ }^{1} \mathrm{H} \mathrm{NMR}\left(\mathrm{CDCl}_{3}, 600 \mathrm{MHz}\right) \delta 1.23(3 \mathrm{H}$, 
d, $J=6.6 \mathrm{~Hz}, \mathrm{H}-8), 3.46(3 \mathrm{H}, \mathrm{d}, J=1.3 \mathrm{~Hz}, \mathrm{OMe}), 4.03(1 \mathrm{H}, \mathrm{dd}, J=5.8$, $2.9 \mathrm{~Hz}, \mathrm{H}-6), 4.27(1 \mathrm{H}, \mathrm{dq}, J=3.1,2.2 \mathrm{~Hz}, \mathrm{H}-2), 4.59(1 \mathrm{H}, \mathrm{dt}, J=5.1$, $2.5 \mathrm{~Hz}, \mathrm{H}-5), 5.21(1 \mathrm{H}, \mathrm{qd}, J=6.6,3.1 \mathrm{~Hz}, \mathrm{H}-7), 6.04(1 \mathrm{H}, \mathrm{d}, J=10.2$ $\mathrm{Hz}, \mathrm{H}-3), 6.09$ (1H, ddd, $J=10.2,5.1,2.2 \mathrm{~Hz}, \mathrm{H}-4), 6.16(1 \mathrm{H}, \mathrm{d}, J=9.8$ $\left.\mathrm{Hz}, \mathrm{H}-2^{\prime}\right), 6.80\left(1 \mathrm{H}, \mathrm{dd}, J=9.8,5.8 \mathrm{~Hz}, \mathrm{H}-1^{\prime}\right) ;{ }^{13} \mathrm{C} \mathrm{NMR}\left(\mathrm{CDCl}_{3}\right.$, $151 \mathrm{MHz}) \delta 13.7$ (C-8), $54.5(\mathrm{OMe}), 64.0$ (C6), 68.2 (C-5), 72.4 (C-7), 75.3 (C-2), 122.7 (C-4), 123.8 (C-2'), 130.1 (C-3), 138.7 (C-1') (Supplementary Figures 16-18).

The raw NMR data files of the isolated compounds are available at the following link: https://doi.org/10.26037/yareta: k4p3ozyehbhg5nr4s7iuc5tkf4

\section{MTT Assay}

Indicated cell lines were detached and resuspended at 120,000 cells $/ \mathrm{ml}$ and added to each well of a transparent 384-well plate in the final volume of $25 \mu \mathrm{l} /$ well. The cells were maintained in DMEM containing $10 \% \mathrm{FBS}$ at $37^{\circ} \mathrm{C}, 5 \% \mathrm{CO}_{2}$ overnight. The next day, the medium in each well was replaced with $40 \mu$ of the fresh one containing the indicated concentrations of compounds. After incubation for 3 days, the medium in each well was replaced with $25 \mu \mathrm{l}$ of $0.5 \mathrm{mg} / \mathrm{ml}$ thiazolyl blue solution in 1xPBS followed by incubation for $3 \mathrm{~h}$ at $37^{\circ} \mathrm{C}$. Then, the solution was removed and $25 \mu \mathrm{l}$ DMSO was added to each well. Absorbance at $510 \mathrm{~nm}$ was measured in a Tecan Infinite M200 PRO plate reader.

\section{Wnt Activity Evaluation}

The Wnt-induced and basal luciferase activities were analyzed as described (Koval et al., 2014; Shaw et al., 2019b). BT-20 TNBC cell line stably transfected with TopFlash reporter plasmid was seeded at 240,000 cells $/ \mathrm{ml}$ in a white opaque 384 -well plate in the final volume of $25 \mu \mathrm{l}$. The cells were maintained incubated at $37^{\circ} \mathrm{C}, 5 \% \mathrm{CO}_{2}$ overnight for attachment. Subsequently, they were transfected by a plasmid encoding Renilla luciferase under the CMV promoter as described in the manufacturer's protocol using $12 \mu \mathrm{g} / \mathrm{ml}$ of DNA and $40 \mu \mathrm{l} / \mathrm{ml}$ XtremeGENE 9 reagent. The next day, the medium in each well was replaced with a $20 \mu \mathrm{l}$ fresh medium containing Wnt3a $(2.5 \mu \mathrm{g} / \mathrm{ml})$ or GSK3 $\beta$ inhibitor CHIR99021 (Koval and Katanaev, 2011). After overnight incubation, the supernatant in each well was removed, and the luciferase activity was measured as described (Koval et al., 2014).

To measure the activity of luciferases, the culture medium was completely removed from all wells of the plate. Next, the luciferase activity of the firefly and Renilla luciferases was detected sequentially in individual wells of a 384-well plate through injection of corresponding measurement solutions in Infinite $\mathrm{M}$ Plex multifunctional plate reader with injection module (Dyer et al., 2000).

\section{REFERENCES}

Allard, P.-M., Péresse, T., Bisson, J., Gindro, K., Marcourt, L., Pham, V. C., et al. (2016). Integration of Molecular Networking and In-Silico MS/MS Fragmentation for Natural Products Dereplication. Anal. Chem. 88 (6), 3317-3323. doi:10.1021/acs.analchem.5b04804

Andolfi, A., Maddau, L., Cimmino, A., Linaldeddu, B. T., Basso, S., Deidda, A., et al. (2014). Lasiojasmonates A-C, Three Jasmonic Acid Esters Produced by

\section{DATA AVAILABILITY STATEMENT}

The raw data supporting the conclusions of this article will be made available by the authors, without undue reservation.

\section{AUTHOR CONTRIBUTIONS}

LP, KG, EF, LM, and J-LW contributed to the conception and design of the study. LP, AK, BD, LM, NL, KG, and ST organized and performed the experiments. LP, AK, LM, and L-MQ-G performed the data analysis. LP and AK wrote the first draft of the article. LP, AK, EF, LM, VK, and J-LW wrote and edited further versions. JC designed and performed the ecological sampling and complementary metagenomic analysis. All authors read, reviewed, and approved the article.

\section{FUNDING}

This work has benefited from a joint Agence Nationale de la Recherche-Swiss National Science Foundation (ANR-SNF) grant (SECIL, ref ANR-15-CE21-0016, and SNF n³10030E-164289).

\section{ACKNOWLEDGMENTS}

The authors thank Pierre-Marie Allard and Arnaud Gaudry for fruitful discussions on molecular network. The authors acknowledge the Agence Nationale de la Recherche and the Swiss National Science Foundation for the funding of the SECIL project (SECIL, ref ANR-15-CE21-0016 and SNF $\left.\mathrm{n}^{\circ} 310030 \mathrm{E}-164289\right)$. The Institute of Pharmaceutical Sciences of Western Switzerland of the University of Geneva (J-LW) is thankful to the Swiss National Science Foundation for the support in the acquisition of the NMR $600 \mathrm{MHz}$ (SNF R'Equip grant 316030_164095). L-MQ-G is thankful for the scholarship (N_214171-025) from Ministerio de Ciencia, Tecnología y Telecomunicaciones, MICITT, Costa Rica.

\section{SUPPLEMENTARY MATERIAL}

The Supplementary Material for this article can be found online at: https://www.frontiersin.org/articles/10.3389/fchem.2021.664489/ full\#supplementary-material

Lasiodiplodia sp., a grapevine Pathogen. Phytochemistry 103, 145-153. doi:10.1016/j.phytochem.2014.03.016

Arnold, A. E., Maynard, Z., Gilbert, G. S., Coley, P. D., and Kursar, T. A. (2000). Are Tropical Fungal Endophytes Hyperdiverse?. Ecol. Lett. 3 (4), 267-274. doi:10.1046/j.1461-0248.2000.00159.x

Arnold, A. E., Mejía, L. C., Kyllo, D., Rojas, E. I., Maynard, Z., Robbins, N., et al. (2003). Fungal Endophytes Limit Pathogen Damage in a Tropical Tree. Proc. Natl. Acad. Sci. 100 (26), 15649-15654. doi:10.1073/ pnas. 2533483100 
Barthélemy, M., Elie, N., Pellissier, L., Wolfender, J.-L., Stien, D., Touboul, D., et al. (2019). Structural Identification of Antibacterial Lipids from Amazonian Palm Tree Endophytes through the Molecular Network Approach. Int. J. Mol. Sci. 20 (8), 2006. doi:10.3390/ijms20082006

Barthélemy, M., Guérineau, V., Genta-Jouve, G., Roy, M., Chave, J., Guillot, R., et al. (2020). Identification and Dereplication of Endophytic Colletotrichum Strains by MALDI TOF Mass Spectrometry and Molecular Networking. Sci. Rep. 10, 19788. doi:10.1038/s41598-020-74852-w

Blagodatski, A., Poteryaev, D., and Katanaev, V. L. (2014). Targeting the Wnt Pathways for Therapies. Mol. Cell Therapies 2 (1), 28. doi:10.1186/2052-8426$2-28$

Burgess, T. I., Barber, P. A., Mohali, S., Pegg, G., de Beer, W., and Wingfield, M. J. (2006). Three New Lasiodiplodia Spp. From the Tropics, Recognized Based on DNA Sequence Comparisons and Morphology. Mycologia 98 (3), 423-435. doi:10.3852/mycologia.98.3.423

Cai, H., Strouse, J., Dumlao, D., Jung, M. E., and Clarke, S. (2001). Distinct Reactions Catalyzed by Bacterial and Yeast Trans-Aconitate Methyltransferases. Biochemistry 40 (7), 2210-2219. doi:10.1021/bi0022902

Cai, Y.-S., Guo, Y.-W., and Krohn, K. (2010). Structure, Bioactivities, Biosynthetic Relationships and Chemical Synthesis of the Spirodioxynaphthalenes. Nat. Prod. Rep. 27 (12), 1840-1870. doi:10.1039/C0NP00031K

Charles-Dominique, P., Chave, J., Dubois, M.-A., De Granville, J.-J., Riera, B., and Vezzoli, C. (2003). Colonization Front of the Understorey Palm Astrocaryum Sciophilum in a Pristine Rain Forest of French Guiana. Glob. Ecol. Biogeogr. 12 (3), 237-248. doi:10.1046/j.1466-822x.2003.00020.x

Choules, M. P., Klein, L. L., Lankin, D. C., McAlpine, J. B., Cho, S.-H., Cheng, J., et al. (2018). Residual Complexity Does Impact Organic Chemistry and Drug Discovery: The Case of Rufomyazine and Rufomycin. J. Org. Chem. 83 (12), 6664-6672. doi:10.1021/acs.joc.8b00988

Cimmino, A., Cinelli, T., Masi, M., Reveglia, P., da Silva, M. A., Mugnai, L., et al. (2017). Phytotoxic Lipophilic Metabolites Produced by Grapevine Strains ofLasiodiplodiaSpecies in Brazil. J. Agric. Food Chem. 65 (6), 1102-1107. doi:10.1021/acs.jafc.6b04906

Correia, K. C., Silva, M. A., De Morais, M. A., Armengol, J., Phillips, A. J. L., Câmara, M. P. S., et al. (2016). Phylogeny, Distribution and Pathogenicity ofLasiodiplodiaspecies Associated with Dieback of Table Grape in the Main Brazilian Exporting Region. Plant Pathol. 65, 92-103. doi:10.1111/ppa.12388

De Wet, J., Slippers, B., Preisig, O., Wingfield, B. D., and Wingfield, M. J. (2008). Phylogeny of the Botryosphaeriaceae Reveals Patterns of Host Association. Mol. Phylogenet. Evol. 46 (1), 116-126. doi:10.1016/j.ympev.2007.08.016

Dictionary of Natural Products on DVD (2020). Dictionary of Natural Products on DVD [Internet]. London: CRC press, Tylor \& Francis Group. Available from: http://dnp.chemnetbase.com/ (Accessed July 4, 2020).

Djoukeng, J. D., Polli, S., Larignon, P., and Abou-Mansour, E. (2009). Identification of Phytotoxins from Botryosphaeria Obtusa, a Pathogen of Black Dead Arm Disease of grapevine. Eur. J. Plant Pathol. 124 (2), 303-308. doi:10.1007/ s10658-008-9419-6

Djoumbou Feunang, Y., Eisner, R., Knox, C., Chepelev, L., Hastings, J., Owen, G., et al. (2016). ClassyFire: Automated Chemical Classification with a Comprehensive, Computable Taxonomy. J. Cheminform 8 (1), 61. doi:10.1186/s13321-016-0174-y

Donald, J., Barthélemy, M., Gazal, N., Eveno, Y., Manzi, S., Eparvier, V., et al. (2019). Tropical Palm Endophytes Exhibit Low Competitive Structuring When Assessed Using Co-occurrence and Antipathogen Activity Analysis. Front. For. Glob. Change 2, 86. doi:10.3389/ffgc.2019.00086

Donald, J., Roy, M., Suescun, U., Iribar, A., Manzi, S., Péllissier, L., et al. (2020). A Test of Community Assembly Rules Using Foliar Endophytes from a Tropical forest Canopy. J. Ecol. 108 (4), 1605-1616. doi:10.1111/13652745.13344

Dyer, B. W., Ferrer, F. A., Klinedinst, D. K., and Rodriguez, R. (2000). A Noncommercial Dual Luciferase Enzyme Assay System for Reporter Gene Analysis. Anal. Biochem. 282 (1), 158-161. doi:10.1006/abio.2000.4605

Gindrat, D., and Pezet, R. (1994). Le Paraquat, un Outil pour la Révélation Rapide d'Infections Fongiques Latentes et de Champignons Endophytes. J. Phytopathol 141 (1), 86-98. doi:10.1111/j.1439-0434.1994.tb01448.x

Glauser, G., Gindro, K., Fringeli, J., De Joffrey, J.-P., Rudaz, S., and Wolfender, J.-L. (2009). Differential Analysis of Mycoalexins in Confrontation Zones of grapevine Fungal Pathogens by Ultrahigh Pressure Liquid Chromatography/
time-Of-Flight Mass Spectrometry and Capillary Nuclear Magnetic Resonance. J. Agric. Food Chem. 57 (4), 1127-1134. doi:10.1021/jf8033539

Guillarme, D., Nguyen, D. T. T., Rudaz, S., and Veuthey, J.-L. (2008). Method Transfer for Fast Liquid Chromatography in Pharmaceutical Analysis: Application to Short Columns Packed with Small Particle. Part II: Gradient Experiments. Eur. J. Pharmaceutics Biopharmaceutics 68 (2), 430-440. doi:10.1016/j.ejpb.2007.06.018

He, G., Matsuura, H., and Yoshihara, T. (2004). Isolation of an Alpha-MethyleneGamma-Butyrolactone Derivative, a Toxin from the Plant Pathogen Lasiodiplodia Theobromae. Phytochemistry 65 (20), 2803-2807. doi:10.1016/ j.phytochem.2004.08.011

Holstein, T. W. (2012). The Evolution of the Wnt Pathway. Cold Spring Harbor Perspect. Biol. 4, a007922. doi:10.1101/cshperspect.a007922

Hoye, T. R., Jeffrey, C. S., and Shao, F. (2007). Mosher Ester Analysis for the Determination of Absolute Configuration of Stereogenic (Chiral) Carbinol Carbons. Nat. Protoc. 2 (10), 2451-2458. doi:10.1038/nprot.2007.354

Kahn, F. (2008). The Genus Astrocaryum (Arecaceae). Rev. Peru Biol. 15, 29-46.

Kahn, M. (2014). Can We Safely Target the WNT Pathway?. Nat. Rev. Drug Discov. 13 (7), 513-532. doi:10.1038/nrd4233

Ke, X., and Shen, L. (2017). Molecular Targeted Therapy of Cancer: The Progress and Future prospect. Front. Lab. Med. 1 (2), 69-75. doi:10.1016/ j.flm.2017.06.001

Kind, T., and Fiehn, O. (2007). Seven Golden Rules for Heuristic Filtering of Molecular Formulas Obtained by Accurate Mass Spectrometry. BMC Bioinformatics 8 (1), 105. doi:10.1186/1471-2105-8-105

Koval, A., and Katanaev, V. L. (2018). Dramatic Dysbalancing of the Wnt Pathway in Breast Cancers. Sci. Rep. 8, 7329. doi:10.1038/s41598-018-25672-6

Koval, A., and Katanaev, V. L. (2011). Wnt3a Stimulation Elicits G-ProteinCoupled Receptor Properties of Mammalian Frizzled Proteins. Biochem. J. 433 (3), 435-440. doi:10.1042/BJ20101878

Koval, A., Purvanov, V., Egger-Adam, D., and Katanaev, V. L. (2011). Yellow Submarine of the Wnt/Frizzled Signaling: Submerging from the G Protein Harbor to the Targets. Biochem. Pharmacol. 82 (10), 1311-1319. doi:10.1016/ j.bcp.2011.06.005

Koval, A. V., Vlasov, P., Shichkova, P., Khunderyakova, S., Markov, Y., Panchenko, J., et al. (2014). Anti-leprosy Drug Clofazimine Inhibits Growth of TripleNegative Breast Cancer Cells via Inhibition of Canonical Wnt Signaling. Biochem. Pharmacol. 87 (4), 571-578. doi:10.1016/j.bcp.2013.12.007

Kunnumakkara, A. B., Bordoloi, D., Sailo, B. L., Roy, N. K., Thakur, K. K., Banik, K., et al. (2019). Cancer Drug Development: The Missing Links. Exp. Biol. Med. (Maywood) 244 (8), 663-689. doi:10.1177/1535370219839163

Kusari, S., Zühlke, S., and Spiteller, M. (2009). An Endophytic Fungus fromCamptotheca acuminataThat Produces Camptothecin and Analogues. J. Nat. Prod. 72 (1), 2-7. doi:10.1021/np800455b

Li, H. L., Jayawardena, R. S., Xu, W., Hu, M., Li, X. H., Liu, J. H., et al. (2019). Lasiodiplodia Theobromae and L. Pseudotheobromae Causing Leaf Necrosis on Camellia Sinensis in Fujian Province, China. Can. J. Plant Pathol. 41 (2), 277-284. doi:10.1080/07060661.2019.1569559

Lü, X., Chen, G., Li, Z., Zhang, Y., Wang, Z., Rong, W., et al. (2014). Palmarumycins from the Endophytic FungusLasiodiplodia pseudotheobromaeXSZ-3. Helvetica Chim. Acta 97 (9), 1289-1294. doi:10.1002/hlca.201300436

Macías-Rubalcava, M. L., Ruiz-Velasco Sobrino, M. E., Meléndez-González, C., and Hernández-Ortega, S. (2014). Naphthoquinone Spiroketals and Organic Extracts from the Endophytic Fungus Edenia Gomezpompae as Potential Herbicides. J. Agric. Food Chem. 62 (16), 3553-3562. doi:10.1021/ jf500965k

Martin, F. M., Uroz, S., and Barker, D. G. (2017). Ancestral Alliances: Plant Mutualistic Symbioses with Fungi and Bacteria. Science 356 (6340), eaad4501. doi:10.1126/science.aad4501

Martínez-Luis, S., Della-Togna, G., Coley, P. D., Kursar, T. A., Gerwick, W. H., and Cubilla-Rios, L. (2008). Antileishmanial Constituents of the Panamanian Endophytic Fungus Edenia Sp. J. Nat. Prod. 71 (12), 2011-2014. doi:10.1021/np800472q

Matsumoto, M., and Nago, H. (1994). (R)-2-Octeno- $\delta$-lactone and Other Volatiles Produced byLasiodiplodia Theobromae. Biosci. Biotechnol. Biochem. 58 (7), 1262-1266. doi:10.1271/bbb.58.1262

Meepagala, K. M., Briscoe, W. E., Techen, N., Johnson, R. D., Clausen, B. M., and Duke, S. O. (2018). Isolation of a Phytotoxic Isocoumarin from Diaporthe 
Eres-infectedHedera helix(English Ivy) and Synthesis of its Phytotoxic Analogs. Pest Manag. Sci. 74 (1), 37-45. doi:10.1002/ps.4712

Mohali, S. R., Castro-Medina, F., Úrbez-Torres, J. R., and Gubler, W. D. (2017). First Report of Lasiodiplodia Theobromae and L. Venezuelensis Associated with Blue Stain on Ficus Insipida wood from the Natural Forest of Venezuela. For. Path. 47 (5), e12355. doi:10.1111/efp.12355

Nakahashi, A., Miura, N., Monde, K., and Tsukamoto, S. (2009). Stereochemical Studies of Hexylitaconic Acid, an Inhibitor of P53-HDM2 Interaction. Bioorg. Med. Chem. Lett. 19 (11), 3027-3030. doi:10.1016/j.bmcl.2009.04.057

Omeje, E. O., Ahomafor, J. E., Onyekaba, T. U., Monioro, P. O., Nneka, I., Onyeloni, S., et al. (2017). Endophytic Fungi as Alternative and Reliable Sources for Potent Anticancer Agents in Natural Products and Cancer Drug Discovery. London: IntechOpen. doi:10.5772/67797

Pereda-Miranda, R., Hernández, L., Villavicencio, M. J., Novelo, M., Ibarra, P., Chai, H., et al. (1993). Structure and Stereochemistry of Pectinolides A-C, Novel Antimicrobial and Cytotoxic 5,6-Dihydro- $\alpha$-Pyrones from Hyptis Pectinata. J. Nat. Prod. 56 (4), 583-593. doi:10.1021/np50094a019

Petrini, O. (1991). "Fungal Endophytes of Tree Leaves," in Microbial Ecology of Leaves [Internet]. Editors JH Andrews and SS Hirano. 1st ed. (New York, NY: Springer(Brock/Springer Series in Contemporary Bioscience)), 179-197. doi:10.1007/978-1-4612-3168-4_9

Pluskal, T., Castillo, S., Villar-Briones, A., and Orešič, M. (2010). MZmine 2: Modular Framework for Processing, Visualizing, and Analyzing Mass Spectrometry-Based Molecular Profile Data. BMC Bioinformatics 11 (395). doi:10.1186/1471-2105-11-395

Queiroz, E. F., Alfattani, A., Afzan, A., Marcourt, L., Guillarme, D., and Wolfender, J.-L. (2019). Utility of Dry Load Injection for an Efficient Natural Products Isolation at the Semi-preparative Chromatographic Scale. J. Chromatogr. A 1598, 85-91. doi:10.1016/j.chroma.2019.03.042

Rahman, M. M., and Gray, A. I. (2005). A Benzoisofuranone Derivative and Carbazole Alkaloids from Murraya Koenigii and Their Antimicrobial Activity. Phytochemistry 66 (13), 1601-1606. doi:10.1016/ j.phytochem.2005.05.001

Reveglia, P., Masi, M., and Evidente, A. (2020). Melleins-Intriguing Natural Compounds. Biomolecules 10 (5), 772. doi:10.3390/biom10050772

Reveglia, P., Savocchia, S., Billones-Baaijens, R., Masi, M., Cimmino, A., and Evidente, A. (2019). Phytotoxic Metabolites by Nine Species of Botryosphaeriaceae Involved in grapevine Dieback in Australia and Identification of Those Produced by Diplodia Mutila, Diplodia Seriata, Neofusicoccum Australe and Neofusicoccum Luteum. Nat. Product. Res. 33 (15), 2223-2229. doi:10.1080/14786419.2018.1497631

Ring, A., Kim, Y.-M., and Kahn, M. (2014). Wnt/Catenin Signaling in Adult Stem Cell Physiology and Disease. Stem Cel Rev Rep 10 (4), 512-525. doi:10.1007/ s12015-014-9515-2

Robert, V., Stegehuis, G., and Stalpers, J. (2005). The MycoBank Engine and Related Databases [Internet]. Available from: https://www.mycobank.org/page/ Simple\%20names\%20search (Accessed Apr 19, 2020).

Rosa, L. H., Vieira, M. L. A., Cota, B. B., Johann, S., Alves, T. M. A., Zani, C. L., et al. (2011). "Endophytic Fungi of Tropical Forests: A Promising Source of Bioactive Prototype Molecules for the Treatment of Neglected Diseases," in Drug Development - A Case Study Based Insight into Modern Strategies. Editor C Rundfeldt (London: InTechOpen). doi:10.5772/27783

Rukachaisirikul, V., Arunpanichlert, J., Sukpondma, Y., Phongpaichit, S., and Sakayaroj, J. (2009). Metabolites from the Endophytic Fungi Botryosphaeria Rhodina PSU-M35 and PSU-M114. Tetrahedron 65 (51), 10590-10595. doi:10.1016/j.tet.2009.10.084

Rutz, A., Dounoue-Kubo, M., Ollivier, S., Bisson, J., Bagheri, M., Saesong, T., et al. (2019). Taxonomically Informed Scoring Enhances Confidence in Natural Products Annotation. Front. Plant Sci. 10, 1329. doi:10.3389/ fpls.2019.01329

Sakemi, S., Inagaki, T., Kaneda, K., Hirai, H., Iwata, E., Sakakibara, T., et al. (1995). CJ-12,371 and CJ-12,372, Two Novel DNA Gyrase Inhibitors. Fermentation, Isolation, Structural Elucidation and Biological Activities. J. Antibiot. 48 (2), 134-142. doi:10.7164/antibiotics.48.134

Salvatore, M. M., Alves, A., and Andolfi, A. (2020). Secondary Metabolites of Lasiodiplodia Theobromae: Distribution, Chemical Diversity, Bioactivity, and Implications of Their Occurrence. Toxins 12 (7), 457. doi:10.3390/ toxins 12070457
Schulz, B., Boyle, C., Draeger, S., Römmert, A.-K., and Krohn, K. (2002) Endophytic Fungi: a Source of Novel Biologically Active Secondary Metabolites. Mycol. Res. 106 (9), 996-1004. doi:10.1017/S0953756202006342

Schulz, B., and Boyle, C. (2006). "What Are Endophytes?" in Microbial Root Endophytes [Internet]Soil Biology. Editors BJE Schulz, CJC Boyle, and TN Sieber (Berlin, Heidelberg: Springer), Vol. 9, 1-13. doi:10.1007/3-540-33526-9_1

Shaw, H. V., Koval, A., and Katanaev, V. L. (2019a). Targeting the Wnt Signalling Pathway in Cancer: Prospects and Perils. Swiss Med. Wkly 149, w20129. doi:10.4414/smw.2019.20129

Shaw, H. V., Koval, A., and Katanaev, V. L. (2019b). A High-Throughput Assay Pipeline for Specific Targeting of Frizzled GPCRs in Cancer. Methods Cel Biol 149, 57-75. doi:10.1016/bs.mcb.2018.08.006

Shen, W., Mao, H., Huang, Q., and Dong, J. (2015). Benzenediol Lactones: a Class of Fungal Metabolites with Diverse Structural Features and Biological Activities. Eur. J. Med. Chem. 97, 747-777. doi:10.1016/j.ejmech.2014.11.067

Smith, H., Wingfield, M. J., Coutinho, T. A., and Crous, P. W. (1996). Sphaeropsis Sapinea and Botryosphaeria Dothidea Endophytic in Pinus Spp. And Eucalyptus Spp. in South Africa. South Afr. J. Bot. 62 (2), 86-88. doi:10.1016/S0254-6299(15)30596-2

Steinhart, Z., and Angers, S. (2018). Wnt Signaling in Development and Tissue Homeostasis. Development 145 (11). doi:10.1242/dev.146589

Stierle, A., Strobel, G., Stierle, D., Grothaus, P., and Bignami, G. (1995). The Search for a Taxol-Producing Microorganism Among the Endophytic Fungi of the Pacific Yew, Taxus Brevifolia. J. Nat. Prod. 58 (9), 1315-1324. doi:10.1021/ np50123a002

Stone, J. K., Bacon, C. W., and White, J. F. (2000). "An Overview of Endophytic Microbes: Endophytism Defined," in Microbial Endophytes [Internet]. Editors C. W Bacon and J. F. White (Boca Raton: CRC Press), 3-29. doi:10.1201/ 9781482277302

Tan, R. X., and Zou, W. X. (2001). Endophytes: a Rich Source of Functional Metabolites (1987 to 2000). Nat. Prod. Rep. 18, 448-459. doi:10.1039/b100918o

Tawfike, A. F., Romli, M., Clements, C., Abbott, G., Young, L., Schumacher, M., et al. (2019). Isolation of Anticancer and Anti-trypanosome Secondary Metabolites from the Endophytic Fungus Aspergillus Flocculus via Bioactivity Guided Isolation and MS Based Metabolomics. J. Chromatogr. B 1106-1107, 71-83. doi:10.1016/j.jchromb.2018.12.032

Tsukada, K., Takahashi, K., and Nabeta, K. (2010). Biosynthesis of Jasmonic Acid in a Plant Pathogenic Fungus, Lasiodiplodia Theobromae. Phytochemistry 71 (17), 2019-2023. doi:10.1016/j.phytochem.2010.09.013

Umeokoli, B. O., Ebrahim, W., El-Neketi, M., Müller, W. E. G., Kalscheuer, R., Lin, W., et al. (2019). A New Depsidone Derivative from Mangrove Sediment Derived Fungus Lasiodiplodia Theobromae. Nat. Product. Res. 33 (15), 2215-2222. doi:10.1080/14786419.2018.1496430

Uranga, C. C., Beld, J., Mrse, A., Córdova-Guerrero, I., Burkart, M. D., and Hernández-Martínez, R. (2016). Fatty Acid Esters Produced by Lasiodiplodia Theobromae Function as Growth Regulators in Tobacco Seedlings. Biochem. Biophysical Res. Commun. 472 (2), 339-345. doi:10.1016/j.bbrc.2016.02.104

Úrbez-Torres, J. R., Castro-Medina, F., Mohali, S. R., and Gubler, W. D. (2016). Botryosphaeriaceae Species Associated With Cankers and Dieback Symptoms of Acacia Mangium and Pinus Caribaea Var. Hondurensis in Venezuela. Plant Dis. 100 (12), 2455-2464. doi:10.1094/PDIS-05-16-0612-RE

Vieira, J. C. B., Câmara, M. P. S., Bezerra, J. D. P., Motta, C. M. S., and Machado, A. R. (2018). First Report of Lasiodiplodia Theobromae Causing Rot in Eggplant Fruit in Brazil. Plant Dis. 102 (10), 2039. doi:10.1094/PDIS-02-180269-PDN

Vogt, A., McPherson, P. A., Shen, X., Balachandran, R., Zhu, G., Raccor, B. S., et al. (2009). High-Content Analysis of Cancer-cell-Specific Apoptosis and Inhibition Ofin VivoAngiogenesis by Synthetic (-)-Pironetin and Analogs. Chem. Biol. Drug Des. 74 (4), 358-368. doi:10.1111/j.17470285.2009.00866.x

Wang, M., Carver, J. J., Phelan, V. V., Sanchez, L. M., Garg, N., Peng, Y., et al. (2016). Sharing and Community Curation of Mass Spectrometry Data with Global Natural Products Social Molecular Networking. Nat. Biotechnol. 34 (8), 828-837. doi:10.1038/nbt.3597

Xu, Y.-M., Mafezoli, J., Oliveira, M. C. F., U'Ren, J. M., Arnold, A. E., and Gunatilaka, A. A. L. (2015). Anteaglonialides A-F and Palmarumycins CE1CE3 from Anteaglonium Sp. FL0768, a Fungal Endophyte of the Spikemoss 
Selaginella Arenicola. J. Nat. Prod. 78 (11), 2738-2747. doi:10.1021/ acs.jnatprod.5b00717

$\mathrm{Xu}, \mathrm{Y}$., Lu, C., and Zheng, Z. (2012). A New 3,4-dihydroisocoumarin Isolated from Botryosphaeria Sp. F00741. Chem. Nat. Compd. 48 (2), 205-207. doi:10.1007/ s10600-012-0205-5

Zhan, T., Rindtorff, N., and Boutros, M. (2017). Wnt Signaling in Cancer. Oncogene 36 (11), 1461-1473. doi:10.1038/onc.2016.304

Zhang, H. W., Song, Y. C., and Tan, R. X. (2006). Biology and Chemistry of Endophytes. Nat. Prod. Rep. 23 (5), 753-771. doi:10.1039/b609472b

Zhou, X.-M., Zheng, C.-J., Wu, J.-T., Chen, G.-Y., Chen, J., and Sun, C.-G. (2016). Five New Lactone Derivatives from the Stems of Dendrobium Nobile. Fitoterapia 115, 96-100. doi:10.1016/j.fitote.2016.10.002

Zhou, Y., Chen, R., Liu, D., Wu, C., Guo, P., and Lin, W. (2017). Asperlin Inhibits LPS-Evoked Foam Cell Formation and Prevents Atherosclerosis in ApoE-/Mice. Mar. Drugs 15 (11), 358. doi:10.3390/md15110358

Zhu, F., Ma, X. H., Qin, C., Tao, L., Liu, X., Shi, Z., et al. (2012). Drug Discovery Prospect from Untapped Species: Indications from Approved Natural Product Drugs. PLoS One 7 (7), e39782. doi:10.1371/ journal.pone.0039782
Conflict of Interest: The authors declare that the research was conducted in the absence of any commercial or financial relationships that could be construed as a potential conflict of interest.

Publisher's Note: All claims expressed in this article are solely those of the authors and do not necessarily represent those of their affiliated organizations, or those of the publisher, the editors and the reviewers. Any product that may be evaluated in this article, or claim that may be made by its manufacturer, is not guaranteed or endorsed by the publisher.

Copyright (C) 2021 Pellissier, Koval, Marcourt, Ferreira Queiroz, Lecoultre, Leoni, Quiros-Guerrero, Barthélémy, Duivelshof, Guillarme, Tardy, Eparvier, Perron, Chave, Stien, Gindro, Katanaev and Wolfender. This is an open-access article distributed under the terms of the Creative Commons Attribution License (CC BY). The use, distribution or reproduction in other forums is permitted, provided the original author(s) and the copyright owner(s) are credited and that the original publication in this journal is cited, in accordance with accepted academic practice. No use, distribution or reproduction is permitted which does not comply with these terms. 